Revista Eletrônica de Direito Processual - REDP.

Rio de Janeiro. Ano 11. Volume 18. Número 2. Maio a Agosto de 2017

Periódico Quadrimestral da Pós-Graduação Stricto Sensu em Direito Processual da UERJ

Patrono: José Carlos Barbosa Moreira. ISSN 1982-7636. pp. 261-296

www.redp.uerj.br

\title{
A NOVA FRONTEIRA DO ACESSO À JUSTIÇA: A JURISDIÇÃO \\ TRANSNACIONAL E OS INSTRUMENTOS DE COOPERAÇÃO \\ INTERNACIONAL NO CPC/2015
}

\section{THE NEW BORDER OF ACCESS TO JUSTICE: THE TRANSNATIONAL JURISDICTION AND THE MECANISMS OF INTERNATIONAL JUDICIAL COOPERATION IN BRAZILIAN CIVIL PROCEDURE CODE OF 2015}

Flávia Pereira Hill Professora Adjunta de Direito Processual Civil da UERJ. Tabeliã no RJ.

flavia.hill@uerj.br

\section{Humberto Dalla Bernardina de Pinho} Professor Titular de Direito Processual Civil na UERJ, IBMEC e Estacio. Promotor de Justiça no RJ. humbertodalla@gmail.com

RESUMO: O presente artigo tem por escopo analisar a jurisdição internacional como uma nova fronteira do acesso à justiça na contemporaneidade, sendo responsável por garantir aos jurisdicionados envolvidos em litígios transnacionais os instrumentos necessários para que tenham os seus direitos tutelados em juízo. Para tanto, o artigo examina os instrumentos de cooperação jurídica internacional no Código de Processo Civil de 2015, com vistas a constatar de qual forma o legislador brasileiro buscou regular o tema na recente codificação.

PALAVAS-CHAVE: Cooperação jurídica internacional; Acesso à Justiça; Código de Processo Civil de 2015.

ABSTRACT: The present article aims to analyze the international jurisdiction as a new border of access to justice nowadays, able to provide the necessary means to guarantee the

\footnotetext{
${ }^{1}$ Artigo recebido em 30/05/2017 e aprovado em 20/07/2017.
} 
Revista Eletrônica de Direito Processual - REDP.

Rio de Janeiro. Ano 11. Volume 18. Número 2. Maio a Agosto de 2017

Periódico Quadrimestral da Pós-Graduação Stricto Sensu em Direito Processual da UERJ

Patrono: José Carlos Barbosa Moreira. ISSN 1982-7636. pp. 261-296

www.redp.uerj.br

observance of rights discussed in international conflicts. The article also studies the mecanisms of international judicial cooperation in the Brazilian Civil Procedure Code of 2015, in order to verify how Brazilian legislators tried to rule the theme in the recent codification.

KEYWORDS: International judicial cooperation; Access to justice; Brazilian Civil Procedure Code of 2015.

SUMÁRIO: 1. A Dimensão Transnacional. 1.1 Considerações iniciais. $1.2 \mathrm{O}$ acesso à justiça na jurisdição transnacional e nos Tratados Internacionais. 2. Direitos fundamentais processuais, harmonização do processo e Direito Processual Transnacional. 3. Direito Processual Transnacional e o conceito de "processo justo". 4. A Cooperação Jurídica Internacional e o papel dos Tribunais nacionais. 5. Mecanismos de cooperação jurídica internacional no Código de Processo Civil de 2015: um sistema preparatório para a consolidação da jurisdição transnacional. 6. Referências bibliográficas

\section{A Dimensão Transnacional}

\subsection{Considerações iniciais}

O Direito Processual foi concebido para a solução de litígios eminentemente internos, ou seja, que envolvem sujeitos oriundos do mesmo país onde a controvérsia será solucionada e atinentes a relações jurídicas que envolvem questões domésticas. Isso se deve à circunstância de o Direito Processual, enquanto ciência social, voltar-se a atender às demandas da sociedade de seu tempo, de acordo com as características apresentadas em dado momento histórico.

E a sociedade, até meados do século XX, estabelecia relações preponderantemente intramuros, dentro dos limites territoriais de cada Estado.

$\mathrm{Na}$ fase autonomista ou conceitual, em que o Direito Processual foi alçado a ramo autônomo do Direito ${ }^{2}$, os principais institutos, que pavimentaram toda a ciência processual, foram cunhados com vistas à solução de litígios internos, sem elementos de estraneidade.

\footnotetext{
${ }^{2}$ A respeito das fases metodológicas na história do processo civil, vide DINAMARCO, Candido Rangel. Instituições de Direito Processual Civil. Volume I. 8. Ed. São Paulo: Malheiros, 2016, pp. 386/390.
} 
Revista Eletrônica de Direito Processual - REDP.

Rio de Janeiro. Ano 11. Volume 18. Número 2. Maio a Agosto de 2017

Periódico Quadrimestral da Pós-Graduação Stricto Sensu em Direito Processual da UERJ

Patrono: José Carlos Barbosa Moreira. ISSN 1982-7636. pp. 261-296

www.redp.uerj.br

A identificação de um elemento de estraneidade era meramente acidental e circunstancial, restrita a casos esporádicos.

No entanto, especialmente a partir de meados do século $\mathrm{XX}$, verifica-se um incremento acelerado do volume de relações estabelecidas além dos limites territoriais dos Estados, passando a sociedade a ostentar contornos que transcendem os critérios de nacionalidade.

Pessoas físicas e jurídicas passaram a estabelecer relações comerciais, profissionais e familiares em diferentes países do globo. Passou-se a falar em negócios internacionais, cadeia internacional de produção e até mesmo em famílias transnacionais, cujos membros são de diferentes nacionalidades.

A esse fenômeno intitulou-se globalização ${ }^{3}$. Aliás, como bem anota Taruffo $^{4}$, tratase de um termo multifacetado, mas que já atinge todas as áreas do direito.

O desenvolvimento de novas tecnologias de comunicação, tais como internet, com a transmissão de imagens, textos e sons quase que em tempo real, e de transporte, tais como aviões e trens extremamente velozes e a preços cada vez mais acessíveis, contribuíram para a formação de uma sociedade globalizada. Trata-se de uma sociedade em que os cidadãos se comunicam, interagem, trocam ideias e estabelecem relações de diferentes ordens (comerciais, profissionais e pessoais) independentemente dos tradicionais conceitos de Estado-nação.

Nessa nova sociedade, os horizontes são mais amplos do que os de outrora ${ }^{5}$.

\footnotetext{
3 "La globalizzazione esige una significativa delocalizzazione della funzione giurisdizionale, che viene a perdere progressivamente i connotati di strumento applicativo del diritto oggettivo sostanziale, a favore di un compito di servizio di risoluzione delle controversie. Al contempo, l'omogeneità e la fungibilità dei sistemi giudiziari costituiscono, per il momento, solo il punto di destinazione di un cammino certamente avanzato, che ha segnato passi importanti, ma che è lungi dall'essersi perfezionato. Si nota così una discrasia fra le finalità del mondo della comunicazione e del commercio globalizzati, da un lato, e la concreta dimensione del dare giustizia, dall'altro. La realtà giudiziaria è ancora fortemente legata alla dimensione nazionale del diritto e costituisce, forse, uno dei segmenti della società più vincolato a profili tradizionali." BIAVATI, Paolo. Deroghe alla giurisdizione statuale e fungibilità dei sistemi giudiziari. Rivista Trimestrale di Diritto e Procedura Civile, Ano 2009, p. 540.

4 "The label "globalization" has become so "loose and possibly rhetorical" and has acquired so many meanings that any attempt to define its contents would be meaningless. Yet, multifaceted and ambiguous as it is, the real phenomenon is under our eyes more every day, and therefore more every day it makes sense to analyze it trying at least to identify some of the effects that it provokes on the administration of justice all around the world. If we assume that the law in general, or at least many areas of the law - if not all - have been, are being or will soon be globalized, then it is meaningful to discuss a topic dealing with the "globalization of procedural justice". It is not enough, however, to introduce such a label-that might also be loose and rhetorical - without trying to deal with some of the most relevant issues that immediately arise from that label". TARUFFO, Michele. Globalizing procedural justice. Some general remarks, in Revista de Processo, vol. 237, nov/2014, São Paulo: Revista dos Tribunais, p. 459.
} 
Revista Eletrônica de Direito Processual - REDP.

Rio de Janeiro. Ano 11. Volume 18. Número 2. Maio a Agosto de 2017

Periódico Quadrimestral da Pós-Graduação Stricto Sensu em Direito Processual da UERJ

Patrono: José Carlos Barbosa Moreira. ISSN 1982-7636. pp. 261-296

www.redp.uerj.br

Retomando-se a premissa traçada inicialmente, sendo o Direito Processual uma ciência social, decerto a formação de uma nova sociedade, a sociedade global, não poderia deixar de ser considerada e suscitar uma reflexão sobre os paradigmas sobre os quais se assenta o processo $^{6}$.

O crescimento do volume de relações no âmbito transnacional ${ }^{7}$ ocasionou, como consequência, o proporcional aumento do número de litígios internacionais que são submetidos ao Poder Judiciário dos Estados, gerando desafios para o Direito Processual.

Desse modo, o que, tradicionalmente, era considerado meramente acidental ou circunstancial, tornou-se frequente.

Passamos a nos deparar com um significativo (e crescente) contingente de demandas judiciais envolvendo jurisdicionados de diferentes nacionalidades ou a respeito de relações jurídicas estabelecidas em diferentes partes do mundo ${ }^{8}$.

Diante disso, o antigo paradigma interno sobre o qual o Direito Processual fora cunhado mostrou-se insuficiente e inapto a solucionar as controvérsias transnacionais ${ }^{9}$.

\footnotetext{
${ }^{5}$ HILL, Flávia Pereira. O Direito Processual Transnacional como forma de acesso à justiça no século XXI. Rio de Janeiro: GZ Editora, 2013, p. 53.

6 "La disciplina delle controversie transnazionali è un aspetto del diritto processuale civile." CAPONI, Remo. Controversie transnazionali ed elementi di giusto processo, in Relazione generale al XIV convegno mondiale dell'Associazione internazionale di diritto processuale, Heidelberg, 26-30 luglio 2011, p. 06.

${ }^{7}$ Preferimos falar em relações e controvérsias transnacionais e, consequentemente, em Direito Processual Transnacional, pois o termo internacional tecnicamente se refere às relações entre governos de Estadosnações, enquanto que o fenômeno ora estudado refere-se a relações estabelecidas entre particulares, sejam pessoas físicas ou jurídicas, de diferentes partes do globo e independentemente de ações ou intervenções governamentais ou institucionais. Trata-se de um movimento espontâneo, decorrente especialmente do incremento das tecnologias de comunicação e transporte ao redor do mundo.

8 "Controversie «transfrontaliere», controversie «transnazionali» sono espressioni impiegate revalentemente nel settore della giustizia civile. Le parti sono di regola soggetti privati. Le due parole «transfrontaliero» e «transnazionale» hanno lo stesso significato, con sfumature linguistiche diverse. Il termine «frontiera» indica il confine territoriale e politico di uno Stato. La definizione tradizionale di controversia transfrontaliera (o transnazionale) è data dall'angolo visuale di questo confine. Così, è transfrontaliera (o transnazionale) la controversia che ha uno o più elementi di contatto con l'estero, cioè con uno spazio esterno rispetto all'ordinamento statale: ad esempio, la cittadinanza, il domicilio o la residenza di una delle parti, l'oggetto del processo, i mezzi di prova o il diritto sostanziale applicabile. Indubbiamente, il fatto che gli elementi della controversia entrino in contatto con una pluralità di spazi territoriali e politici, frequentemente distanti tra di loro, è uno degli aspetti problematici di questa materia. Tuttavia, il termine «nazione» è più comprensivo. Esso indica un insieme di persone che hanno in comune la storia, la cultura, la lingua, il territorio. Esso richiama pressoché tutti gli elementi che contribuiscono a formare una determinata tradizione giuridica e, più specificamente, un determinato pensiero processuale. Il termine controversie «transnazionali» è pertanto preferibile, poiché esso riassume in sé le due cause fondamentali dei problemi in questa materia. In primo luogo, tali controversie sorgono tra parti e vengono gestite da avvocati che vivono in ambienti culturali diversi. In secondo luogo, esse hanno elementi collocati in una pluralità di spazi territoriali e politici. Il rischio di incomprensioni linguistiche e culturali è molto alto, come sono notevoli i costi di tempo e di denaro della gestione della controversia." CAPONI, Remo. Controversie transnazionali ed elementi di giusto processo, in Relazione generale al XIV convegno mondiale dell'Associazione internazionale di diritto processuale, Heidelberg, 26-30 luglio 2011, pp. 78-79.
} 
Revista Eletrônica de Direito Processual - REDP.

Rio de Janeiro. Ano 11. Volume 18. Número 2. Maio a Agosto de 2017

Periódico Quadrimestral da Pós-Graduação Stricto Sensu em Direito Processual da UERJ

Patrono: José Carlos Barbosa Moreira. ISSN 1982-7636. pp. 261-296

www.redp.uerj.br

Mauro Cappelletti destacou, na última década do século $\mathrm{XX}$, a necessidade de se atentar para a dimensão transnacional do processo civil, diante das mudanças verificadas na sociedade ${ }^{10}$.

A globalização da economia, da cultura e das relações sociais gerou consequências jurídicas que, segundo Michele Taruffo, ocasionaram a mitigação da tradicional relação entre jurisdição, soberania e território do Estado-nação ${ }^{11}$. Taruffo destaca a importância de se atentar para a nova "dimensão transnacional da justiça civil", decorrente dessa nova sociedade global $^{12}$.

Remo Caponi aponta como desafios a serem superados os obstáculos ao acesso à justiça nos diferentes Estados nacionais, em razão da demora e dos altos custos para a solução das controvérsias transnacionais, colocando em evidência a morosidade dos procedimentos internos de reconhecimento e execução de decisões estrangeiras ${ }^{13}$.

\footnotetext{
9 "Dal punto di vista del diritto, uno degli effetti principali della globalizzazione è quindi l'attenuazione del legame fra la persona e un dato territorio. Ovviamente, mi riferisco ad un profilo tendenziale, perché non tutto il mondo è soggetto in modo uniforme a questi fenomeni: accanto ad aree, se così mi posso esprimere, fortemente globalizzate, altre ve ne sono che tuttora sfuggono, in misura più o meno accentuata, a questo sviluppo. Tuttavia, nell'area dei paesi ad economia industriale, di cui l'Italia fa parte, l'elemento sopra riferito è reale e verificabile. È questo l'àmbito in cui si deve muovere oggi il diritto e, in specie, per quanto concerne il mio contributo odierno, il diritto giudiziario. Sempre schematizzando, mi pare che siano tre le linee su cui la globalizzazione produce effetti: la tendenza a favorire regole omogenee di diritto sostanziale, attraverso un potenziato riconoscimento della volontà delle parti; la caduta del legame fra territorio, legge applicabile e giurisdizione competente; infine, il rafforzamento delle spinte alla privatizzazione della giustizia." BIAVATI, Paolo. Deroghe alla giurisdizione statuale e fungibilità dei sistemi giudiziari. Rivista Trimestrale di Diritto e Procedura Civile, Ano 2009, p. 524.

${ }^{10}$ CAPPELLETTI, Mauro. Dimensioni della giustizia nelle società contemporanee. Studi di diritto giudiziario comparato. Bolonha: IL Mulino. 1994.

${ }_{11}$ "Ciò vale anche per le conseguenze giuridiche che derivano dalla globalizzazione dell'economia, dei mercati finanziari, del commercio, della cultura e di infiniti altri aspetti della vita economica e sociale, ma studi recenti hanno cominciato a mettere in luce alcuni aspetti rilevanti di queste conseguenze. A proposito della giurisdizione si può osservare in linea generale che la globalizzazione comporta un'accentuazione del fenomeno che è stato opportunamente indicato come "delocalizzazione ", ossia l'allentamento, e al limite estremo l'eliminazione, del tradizionale rapporto tra giurisdizione, sovranità e territorio dello Stato-nazione." TARUFFO, Michele. "Note sulla dimensione transnazionale delle controversie civili". In Rivista Trimestrale di Diritto e Procedura Civile. Milão: Giuffrè. 2001. Versão eletrônica anual, p. 1.062.

12 "(...) sembra che anche i processualisti stiano diventando consapevoli delle dimensioni transnazionali e transculturali della giustizia civile." TARUFFO, Michele. "Dimensioni transculturali della giustizia civile". Rivista Trimestrale di Diritto e Procedura Civile. Milão: Giuffrè. 2000. Versão eletrônica anual. p. 1.083.

13 "Un notevole ostacolo all'efficienza della giustizia civile in un mercato unico è costituito dai diversi e spesso poco conosciuti ordinamenti processuali nazionali, da barriere di accesso alla giustizia civile nazionale per le parti straniere, nonché da lunghi e costosi procedimenti di riconoscimento e di esecuzione dei provvedimenti giurisdizionali stranieri." CAPONI, Remo. "Controversie transnazionali ed elementi di giusto processo". In Relazione generale al XIV convegno mondiale dell'Associazione internazionale di diritto processuale, Heidelberg, 26-30 luglio 2011, p. 79.
} 
Revista Eletrônica de Direito Processual - REDP.

Rio de Janeiro. Ano 11. Volume 18. Número 2. Maio a Agosto de 2017

Periódico Quadrimestral da Pós-Graduação Stricto Sensu em Direito Processual da UERJ

Patrono: José Carlos Barbosa Moreira. ISSN 1982-7636. pp. 261-296

www.redp.uerj.br

Podemos apontar dois grandes eixos evolutivos, como consequência dos novos desafios ${ }^{14}$ trazidos pela sociedade globalizada: (i) Valorização dos direitos fundamentais processuais, com a consequente harmonização dos sistemas processuais nacionais; (ii) Fomento da Cooperação Jurídica Internacional, com a criação de instrumentos processuais aptos a facilitar a circulação e o cumprimento de decisões judiciais estrangeiras e a prática de atos processuais relacionados a processos judiciais alienígenas.

A partir de tais iniciativas, o Direito Processual procura oferecer novas perspectivas para a adequada solução das controvérsias transnacionais, de modo a oferecer soluções efetivas, justas e céleres ${ }^{15}$.

14 "La definizione tradizionale di controversia transnazionale è semplice, ma rivela già una pluralità aspetti critici. Innanzitutto, essa indica il problema: individuare i limiti di esercizio del potere giurisdizionale dell'ordinamento statale rispetto ad altri ordinamenti. In secondo luogo, essa rivela il criterio per risolverlo: gli elementi di contatto e di estraneità della controversia sono misurati rispetto al territorio statale nel quale è esercitato il potere giurisdizionale. In terzo luogo, essa rivela il ruolo centrale svolto dalla sovranità statale. La giurisdizione è un aspetto della sovranità statale. Poiché quest'ultima si esercita in un determinato territorio, la giurisdizione incontra i propri limiti nei confini statali. La globalizzazione dei rapporti sociali ed economici produce certamente controversie che è difficile far rientrare immediatamente in questa dimensione tradizionale, come quelle che sorgono in Internet o nei mercati globali. Più in generale, gli ordinamenti giuridici nazionali incontrano difficoltà nel regolamentare in modo efficiente i rapporti transnazionali. La disciplina di questi ultimi tende a trasferirsi dal piano statale al piano internazionale." CAPONI, Remo. Controversie transnazionali ed elementi di giusto processo, in Relazione generale al XIV convegno mondiale dell'Associazione internazionale di diritto processuale, Heidelberg, 26-30 luglio 2011, p. 80 .

15 "Ma, come rilevato, la funzione di guida e il controllo di intere vicende economiche transnazionali richiede che tutti gli stati (o la gran parte) vi siano coinvolti. Essa si attua, innanzitutto, con l'adeguamento effettivo dell'ordine proprio di ciascuno stato ai princìpi concordati con gli altri, o stabiliti da organizzazioni internazionali cui sia stato conferito il potere d'imporli. (...). Inoltre, gli stati non possono recalcitrare di fronte alla devoluzione di sovranità a nuovi organismi, da creare d'accordo e munire d'imperio per un efficace controllo di tutti i percorsi dell'economia. Particolare interesse dev'essere nutrito per la istituzione di corti transnazionali di giustizia e per la loro investitura rispetto a litiganti privati e pubblici. Ovviamente, il processo di transizione verso un vasto « diritto comune » non comprende soltanto l'esercizio di poteri autoritativi, interni e internazionali, ma coinvolge l'attività di tutti gli 'operatori giuridici'. Ciò è confermato dallo svolgimento della prima fase, da tempo in corso: quella dell'« armonizzazione » fra diritti. Essa dipende solo in parte da misure cogenti, e si realizza soprattutto nell'esperienza concreta: vi fanno spicco le pratiche negoziali di cui si è accennato, le attività degli esperti in esse implicati; l'opera dei giudici, pubblici e privati, e quella dei « dottori ». Questi ultimi Đ giudici e dottrinari Đ uniscono alla capacità professionale di cogliere le manifestazioni del diritto, dalle più evidenti alle più oscure, una «naturale » propensione all'obiettività; perciò possono fruire di un ascolto privilegiato (si pensi, come a paradigma, al loro contributo alla formazione, laboriosamente incorso, di un diritto comune europeo). Comunque, a tutti è richiesto, ora e nel prosieguo, una utilizzazione più incisiva degli strumenti che gli assetti vigenti pro tempore mettono a disposizione. Ciò vale tanto per i poteri pubblici quanto per i soggetti privati (singoli od enti): essi debbono, nei limiti delle rispettive legittimazioni, indirizzare le loro attività verso punti più avanzati di equilibrio e coesistenza fra valori." FAZZALARI, Elio. 'Mondializzazione', politica, diritto. Rivista Trimestrale di Diritto e Procedura Civile, ano 2000, Milão: Giuffrè, p. 689. 
Revista Eletrônica de Direito Processual - REDP.

Rio de Janeiro. Ano 11. Volume 18. Número 2. Maio a Agosto de 2017

Periódico Quadrimestral da Pós-Graduação Stricto Sensu em Direito Processual da UERJ

Patrono: José Carlos Barbosa Moreira. ISSN 1982-7636. pp. 261-296

www.redp.uerj.br

1.2. O acesso à justiça na jurisdição transnacional e a importância dos Tratados Internacionais

Cappelletti ${ }^{16}$ reconhece que nas últimas décadas o movimento pelo acesso à justiça teve êxito em promover mudanças normativas e institucionais em diferentes locais do mundo, respondendo à crise do direito e da justiça ${ }^{17}$.

Contudo, dentro de um contexto globalizado, é imperioso que o estudo dos princípios trazidos pelo professor Paulo Cezar Pinheiro Carneiro também leve em conta uma perspectiva transnacional da jurisdição. Assim sendo, o movimento dever assumir também a tarefa de um projeto de reforma, utilizando toda a riqueza do método comparativo $^{18}$.

Aliás, como bem anota Taruffo ${ }^{19}$, globalização é uma expressão que engloba diversos conceitos, mas, seja como for, influencia fortemente todas as áreas do direito.

\footnotetext{
${ }^{16} \mathrm{Na}$ verdade a mudança foi mais profunda, como adverte o idealizador das "ondas renovatórias": "come movimento di pensiero, l'accesso alla giustizia ha espresso una forte reazione contro un'impostazione dogmático-formalistica che pretendeva di identificare il fenômeno giuridico exclusivamente nel complesso delle norme, essenzialmente di derivazione statale, di un determinato Paese. Il dogmatismo giuridico è stato una forma degenerativa del positivismo giuridico, che ha portato non soltanto ad una semplificazione irrealistica del diritto, ridotto appunto al suo aspetto normativo - jus positum trascurandone così gli altri non meno essenziali elementi: soggeti, istituzioni, procedimenti; ma ha portato altresì ad una non meno irrealistica semplificazione dei compiti e delle responsabilità del giurista, giudice, avvocato, studioso, compiti che, secondo quella impostazione, dovrebbero limitarsi ad una mera, asettica, passiva e meccanica conoscenza ed applicazione delle norme nella vita pratica, nell'insegnamento e nell'analisi scientifica". CAPPELLETTI, Mauro. Dimensioni della Giustizia nelle società Contemporanee, Bologna: Mulino, 1994, p. 72.

${ }^{17}$ Como já registrava Calamandrei: "La crisi della legge, che è crisi del diritto tout court, finisce per trasmettersi e riflettersi nella crisi della giustizia, essendo sin troppo evidente quanto la produzione delle regole sia attività intimamente connessa con la interpretazione delle stesse; al disordine derivante da un caotico, alluvionale e sciatto sistema di produzione di regole si aggiunge, dunque, il disordine rappresentato da un'imprevedibile, caotica ed altrettanto disordinata giurisprudenza; se a ciò aggiungiamo le lungaggini e le gravi inefficienze del sistema giudiziario risulta ben chiaro come la crisi della legge, oltre ad essere causa della fiducia nella giustizia, rischia di minare le stesse fondamenta democratiche delle nostre istituzioni". CALAMANDREI, Piero. La crisi della Giustizia. In: CARNELUTTI, Francesco et.al. La crisi dell diritto. Padova: Cedam, 1953, p. 175.

${ }^{18}$ Vale a pena transcrever as palavras de Cappelletti ao reconhecer a enorme importância do método comparativo em seu trabalho: "È appena il caso de sottolineare l'enorme importanza dello studio comparativo in quest opera di progettazione di riforme. L'analisi comparativa exercita infatti, nelle scienze social, lo stesso ruolo del laboratório sperimentale nelle scienze naturali, perché rede possibile la sperimentazione di soluzioni adottate da vari Paesi, la ricerca delle ragioni di successi e insuccessi, la scoperta, infine, di grandi tendenze evolutive e quindi la previsione delle probabili direzioni future. Il método comparativo aiuta, fra l'altro, a superare, con critério realistici e non meramente speculativi, i limiti e le inadeguatezze, da un lato, di un puro empirismo nella ricerca dei dati - una ricerca nella quale il diritto positivo è accolto avalutativamente - e dall altro lato, di un método di valutazione astratta e apriorística, tipico delle tradizionali impostazioni giusnaturalistiche”. CAPPELLETTI, Mauro. Op. cit., p. 79.

19 "The label "globalization" has become so "loose and possibly rhetorical" and has acquired so many meanings that any attempt to define its contents would be meaningless. Yet, multifaceted and ambiguous as it is, the real phenomenon is under our eyes more every day, and therefore more every day it makes sense to analyze it trying at least to identify some of the effects that it provokes on the administration of justice all
} 
Revista Eletrônica de Direito Processual - REDP.

Rio de Janeiro. Ano 11. Volume 18. Número 2. Maio a Agosto de 2017

Periódico Quadrimestral da Pós-Graduação Stricto Sensu em Direito Processual da UERJ

Patrono: José Carlos Barbosa Moreira. ISSN 1982-7636. pp. 261-296

www.redp.uerj.br

Jurisdição transnacional caracteriza-se como aquela em que há a necessidade de prática de atos processuais perante mais de um Estado para que se decida sobre o bem da vida postulado. Exemplos disso são a homologação de sentença estrangeira (CPC/2015, arts. 960/965) e a colaboração internacional (CPC/2015, arts. 26/41), institutos que receberam especial atenção da Comissão e dos legisladores do novo Código de Processo Civil.

Importante, entretanto, não se olvidar da advertência feita por Chase $^{20}$, de que as diferenças culturais ${ }^{21}$ e de tradição entre os ordenamentos jurídicos não pode ser desprezada, principalmente quando se compara ordenamentos originados das famílias do civil e do common law ${ }^{22}$, apesar de não se poder excluir os diálogos entre eles, tomados os devidos cuidados ${ }^{23}$.

Dentro desse contexto, há dois posicionamentos. Por um lado, há quem enxergue a possibilidade de efetiva integração, acarretando um processo transnacional ${ }^{24}$, inclusive

around the world. If we assume that the law in general, or at least many areas of the law - if not all - have been, are being or will soon be globalized, then it is meaningful to discuss a topic dealing with the "globalization of procedural justice". It is not enough, however, to introduce such a label-that might also be loose and rhetorical - without trying to deal with some of the most relevant issues that immediately arise from that label". TARUFFO, Michele. Globalizing procedural justice. Some general remarks, in Revista de Processo, vol. 237, nov/2014, São Paulo: Revista dos Tribunais, p. 459.

20 "I have argued in previous papers that the transplantation of procedures from one society to another raises an issue even more important than the instrumental question of whether the borrowed approach will work in a new setting: How will the new procedures impact on the society that adopts them? What broader cultural changes - for good or ill - may be set in motion? Underlying these concerns are the subsidiary claims that (1) the formal procedures of dispute resolution found in any culture reflect and express its metaphysics and its values; and (2) dispute procedures, because they are so public, dramatic, and repetitive, are in turn one of the processes (rituals, if you will) by which social values and understandings are communicated and are therefore critical to the ongoing job of transmitting and maintaining culture". CHASE, Oscar G. American "Exceptionalism" and Comparative Procedure, in American Journal of Comparative Law, vol. 50, Spring 2002, p. 277, acesso via www.westlaw.com, em 15 de março de 2013.

${ }^{21}$ Impossível, nessa temática, não fazer alusão à pioneira obra sobre o tema no direito brasileiro: LACERDA, Galeno. Processo e cultura. In: Revista de Direito Processual Civil, São Paulo, v. 3, p. 74-86, 1961.

${ }^{22}$ HAZARD, Geoffrey C. TARUFFO, Michele. Transnational Rules of Civil Procedure, in Cornell International Law Journal, vol. 30, 1997, p. 493.

23 "While I would never claim that cultures are entirely static or that new procedures cannot be borrowed from one to another, even sometimes successfully, there is overwhelming evidence that cultural values and procedural arrangements tend to persist over time. Still, I must admit that there is a tautological aspect to the claim that procedures should not be borrowed because they cannot be borrowed. My method is not so crude; it only predicts difficulty in borrowing from cultures which differ in important values and attitudes. This method also alerts us to the dangers of even successful borrowing by reminding us that a price will be paid in more common currency: the procedures we adopt will affect the culture as surely as they are affected by it". CHASE, Oscar. Culture and Disputing. Tulane Journal of International and Comparative Law, vol. 7, Spring 1999, p. 84, acesso via www.westlaw.com, em 14 de abril de 2013.

24 "In undertaking international harmonization of procedural law, the Reporters have come to identify both fundamental similarities and fundamental differences among procedural systems. Obviously, it is the fundamental differences that present the difficulties. However, it is important to keep in mind that all modern systems of civil procedure have fundamental similarities. These similarities result from the fact that 
Revista Eletrônica de Direito Processual - REDP.

Rio de Janeiro. Ano 11. Volume 18. Número 2. Maio a Agosto de 2017

Periódico Quadrimestral da Pós-Graduação Stricto Sensu em Direito Processual da UERJ

Patrono: José Carlos Barbosa Moreira. ISSN 1982-7636. pp. 261-296

www.redp.uerj.br

informado pelos seus próprios princípios ${ }^{25}$ e compatibilizado com os ditames do justo processo $^{26}$. Por outro lado, há quem entenda pela desnecessidade de formação de um processo transnacional, devendo eventuais controvérsias nesse campo ser resolvidas no âmbito privado ${ }^{27}$. Estamos com a primeira posição, e falaremos mais sobre o tema no tópico seguinte.

Aliás, como bem observa Barroso $^{28}$, essa integração já atinge as Cortes Superiores de diversos países, por meio de referências recíprocas e intercâmbio acadêmico. Ainda que, como adverte Caponi ${ }^{29}$, essa tarefa demande algum esforço.

a procedural system must respond to several inherent requirements. Recognition of these requirements makes easier the task of identifying functional similarities in diverse legal systems and, at the same time, puts into sharper perspective the ways in which procedural systems differ from one another. The fundamental similarities among procedural systems can be summarized as follows: Standards governing assertion of personal jurisdiction and subject-matter jurisdiction, Specifications for a neutral adjudicator, Procedure for notice to defendant, Rules for formulation of claims, Explication of applicable substantive law, Establishment of facts through proof, Provision for expert testimony, Rules for deliberation, decision, and appellate review, and Rules of finality of judgments". HAZARD, Geoffrey C., TARUFFO, Michele. STURNER, Rolf. GIDI, Antonio. Principles and Rules of Transnational Civil Procedure, in New York University Journal of International Law \& Politics, vol. 33, Spring 2001, p. 769, acesso via westlaw.com em fevereiro de 2014.

${ }^{25}$ TARUFFO. Michele. Principles and rules of transnational civil procedure: an evidentiary epistemology, in Penn State International Law Review, vol. 25, p. 509, acesso via westlaw.com em março de 2014.

${ }^{26}$ CAPONI, Remo. Controversie transnazionali ed elementi di giusto processo, Relazione generale al XIV convegno mondiale dell'Associazione internazionale di diritto processuale, Heidelberg, julho de 2011, original gentilmente cedido pelo autor.

27 "I doubt the need for transnational rules of procedure. Contracting parties can better achieve the aims of these Rules by expertly drafted arbitration agreements. If drafters of arbitration agreements wish to incorporate procedural rules by reference, there are rules better designed for arbitration, such as the rules of the American Arbitration Association. Injured consumers suing foreign manufacturers should no more be deprived of home-court procedures than they should be deprived of the ability to sue at home or to have their substantive rights determined by local law. Transnational corporations are not strangers to suits far from their headquarters. They can afford the best local counsel to protect their rights. If transnational rules of procedure are desirable, the Hazard-Taruffo Rules should be amended to increase fairness. The Rules do not protect against having to defend in an inconvenient forum". WEINTRAUB, Russel J. Critique of the HazardTaruffo Transnational Rules of Civil Procedure, inTexas International Law Journal, vol 33, Summer 1998, p. 413.

28 "In recent years, constitutional and supreme courts all over the world began to engage in a growing constitutional dialogue involving mutual citation, academic interchange and public for a such as the Venice Commission. Two factors have contributed to the deepening of this process. First, countries that are newcomers to the rule of law often draw from the experience of more seasoned democracies. In the past several decades we have watched waves of democratization across the world, including Europe in the 1970s (Greece, Portugal and Spain), Latin America in the 1980s (Brazil, Chile, Argentina) and Eastern and Central Europe in the 1990s. Courts like the U.S. Supreme Courts or the German Constitutional Court have served as a significant role model for these new democracies. Although the flow of ideas is more intense in one direction, it is also true that, as with any other exchange, this is a two-way avenue. The second factor involves the sharing of experiences among more mature and traditional democracies. Highly complex and plural societies face common challenges in areas that range from national security to racial, religious and sexual matters. Foreign decisions may offer new information and perspectives, and can also help build consensus". BARROSO, Luis Roberto. 'Here, there and everywhere': human dignity in contemporary law and in the transnational discourse, Boston College International and Comparative Law Review, Vol. 35, No. 2, 
Revista Eletrônica de Direito Processual - REDP.

Rio de Janeiro. Ano 11. Volume 18. Número 2. Maio a Agosto de 2017

Periódico Quadrimestral da Pós-Graduação Stricto Sensu em Direito Processual da UERJ

Patrono: José Carlos Barbosa Moreira. ISSN 1982-7636. pp. 261-296

www.redp.uerj.br

Nesse ponto, é ainda mais relevante o fortalecimento do direito à informação. Para além dos cidadãos saberem dos mecanismos a seu alcance em seu país, é imprescindível, também, que os sujeitos, uma vez que se vejam ligados a conflitos transnacionais, tenham ciência do seu direito e da forma como exercê-lo, dada a realidade globalizada.

Nota-se, atualmente, que, no âmbito dos juizados especiais, as causas de diminuto valor econômico, e no das ações coletivas, pelo Ministério Público ou pelas associações, há, até, um nível satisfatório de conhecimento dos mecanismos de que se pode lançar mão em nível nacional. Na esfera transnacional, diversamente, a ignorância quanto aos meios processuais e aos instrumentos cabíveis transparece de forma quase absoluta.

Destaque-se que o desconhecimento desse viés inclui os próprios operadores do direito, porque, usualmente, essa ótima transnacional não é passada aos alunos no âmbito da graduação.

As questões relacionadas ao Direito Processual Transnacional também precisam ser consideradas à luz do subprincípio da operosidade. Dado o significativo aumento de processos desse tipo, considerando-se a deficiente formação da área, os agentes públicos devem ter especial atenção para que se promova uma adequada tutela das partes.

As demandas internacionais também requerem especial cuidado em relação aos custos do processo, para não inviabiliza-las. Isso porque, pelo baixo número de advogados especializados na área, a contratação deles encarece consideravelmente.

2012, disponível em http://papers.ssrn.com/sol3/papers.cfm?abstract_id=1945741, acesso em 30 de janeiro de 2016.

29 "As cortes mantêm relações recíprocas e dialogam de diversos modos, que são estudados segundo o quadro que os regula e o setor das ciências que neles se aprofunda. Normalmente, em todo serviço judiciário, as cortes entram em contato com a atividade de outras cortes. Na aplicação de parâmetros normativos a fatos da vida para a composição de danos civis, a gestão de interesses de menores, incapazes etc., ou a punição de delitos, sucede raramente que as cortes deduzam os elementos úteis à decisão exclusivamente da solitária interpretação das normas jurídicas e da atividade das partes do processo. Frequentemente, ao interpretar o parâmetro decisório, elas têm em conta precedentes pronunciados por outras cortes sobre situações de fato similares, especialmente onde o ordenamento invista uma particular Corte na função de assegurar a uniformidade da interpretação do Direito. Pense nas cortes de cassação ou de revisão, mas também na Corte de Justiça da União Europeia, em virtude do reenvio prejudicial. Onde entram em jogo normas constitucionais protegidas por uma corte, é inevitável o chamado à jurisprudência desta última. Onde entram em jogo direitos e liberdades garantidas pela Convenção Europeia dos Direitos do Homem, é inevitável a referência à jurisprudência da Corte de Estrasburgo. Relações entre cortes surgem não somente em relação à decisão da causa, mas também em relação ao desenvolvimento de atividades processuais instrumentais a esta última. O tema - tratado geralmente sob a insígnia de "cooperação judiciária" (em sentido estrito) - abarca, por sua vez, uma multiplicidade de perfis em plena evolução, que, nesta sede, não podem ser nem ao menos elencados". CAPONI, Remo. Diálogo entre Cortes nacionais e Cortes internacionais (trad. Pedro Gomes de Queiroz), Revista de Processo, vol. 233, jul/2014, São Paulo: Revista dos Tribunais, p. 273. 
Revista Eletrônica de Direito Processual - REDP.

Rio de Janeiro. Ano 11. Volume 18. Número 2. Maio a Agosto de 2017

Periódico Quadrimestral da Pós-Graduação Stricto Sensu em Direito Processual da UERJ

Patrono: José Carlos Barbosa Moreira. ISSN 1982-7636. pp. 261-296

www.redp.uerj.br

Diante disso, é necessário o investimento na qualificação de defensores públicos (especialmente os da União), de advogados dativos e de Escritórios Modelos, para que também possam atuar no âmbito dos conflitos transnacionais, auxiliando que a prestação jurisdicional seja efetiva.

No plano transnacional, é importante que se atente não só para o sujeito em juízo, mas igualmente para o objeto da tutela jurisdicional. Por precisar praticar atos processuais perante a jurisdição de mais de um Estado, surge uma série de dificuldades de ordem linguística, jurídica e financeira. Daí a necessidade de um tratamento desigual aos litigantes transnacionais, com o fito de se assegurar a isonomia material ${ }^{30}$.

Destaque-se que todos são destinatários da garantia constitucional da razoável duração do processo, sem distinção. Desse modo, não apenas os contendores internos estão inclusos, mas também os transnacionais. No último, inclusive, justifica-se um especial cuidado, já que a razoabilidade é apurada desde a deflagração da demanda até a atividade satisfativa, com a entrega do bem da vida, o que pode se prolongar ainda mias pela prática de atos processuais perante outro país.

Outro aspecto importante a se destacar sobre a garantia do acesso a uma ordem jurídica justa é a sua previsão em tratados internacionais. O Pacto de San Jose da Costa Rica, Convenção Americana de Direitos Humanos, assegura, no art. $8^{\circ}$, uma série de elementos de imperiosa observância para se assegurar um processo justo aos litigantes.

A Convenção Europeia de Direitos Humanos, por sua vez, também regula no art. $6^{\circ}$, uma série de garantias que formam o direito a um processo equitativo. Naquele continente, destaque-se a importante função da jurisprudência da Corte Europeia de

\footnotetext{
30 "A entrega da prestação jurisdicional nos litígios transnacionais exige a atuação coordenada de magistrados de diferentes países, mas todos eles imbuídos do propósito de garantir a consecução dos mesmos princípios basilares, como o acesso à justiça, a isonomia, a duração razoável do processo e a efetividade, consoante estudamos nos itens precedentes. Essa convergência de propósito decorre precisamente do primado dos princípios fundamentais hoje verificado na ciência jurídica. No entanto, a solução de litígios transnacionais traz desafios peculiares ao julgador, pois coloca em tensão princípios como a soberania estatal, de um lado, e o acesso à justiça aliado à isonomia, de outro. Consoante já tivemos a oportunidade de analisar mais detidamente em momento anterior, verifica-se que a formação do microssistema do Direito Processual Transnacional implica a releitura da tradicional concepção do princípio da soberania, passando-se a deitar o olhar, prevalentemente, sobre o indivíduo, o jurisdicionado. Reforça-se a noção de cooperação entre os magistrados de diferentes Estados, voltando-se todos para o compromisso de garantir a entrega da prestação jurisdicional ao jurisdicionado a que faz jus. Passa-se a compreender que somente mediante a ação complementar, coordenada e cooperativa entre os tribunais de diferentes países, para além da cega e injustificada invocação da soberania como premissa e finalidade em si própria, garantirá a consecução do efetivo acesso à justiça ao jurisdicionado". HILL, Flávia Pereira. O direito processual transnacional como forma de acesso à justiça no século XXI: os reflexos e desafios da sociedade contemporânea para o direito processual e a concepção de um título executivo transnacional. Tese de Doutorado. Uerj, 2013, p. 117.
} 
Revista Eletrônica de Direito Processual - REDP.

Rio de Janeiro. Ano 11. Volume 18. Número 2. Maio a Agosto de 2017

Periódico Quadrimestral da Pós-Graduação Stricto Sensu em Direito Processual da UERJ

Patrono: José Carlos Barbosa Moreira. ISSN 1982-7636. pp. 261-296

wWw.redp.uerj.br

Direitos Humanos, que vem concretizando esse dispositivo, com uma série de decisões determinando os parâmetros e o alcance desse direito ${ }^{31}$.

A estabilização da coisa julgada, por exemplo, foi apontada pela Corte como um dos corolários do acesso à justiça. Além disso, destacou-se a importância de se pensar a efetividade e justiça da prestação jurisdicional também no plano executivo ${ }^{32}$.

Outro elemento fundamental da garantia é a efetivação do contraditório $\operatorname{argumentativo~}^{33}$. Por meio dele, deve-se oportunizar, em igualdade material, às partes a exposição de suas razões com os respectivos elementos instrutórios, submetidos ao crivo do contraditório, de modo a permitir que elas influam verdadeiramente na decisão judicial $^{34}$.

${ }^{31}$ Para um interessante levantamento desses casos, remetemos o leitor à obra de Leonardo Schenk. SCHENK, Leonardo Faria. Breve relato histórico das reformas processuais na Itália. Um problema constante: a lentidão dos processos cíveis. Revista Eletrônica de Direito Processual, Rio de Janeiro, v. 2, p. 181-202, 2008. Disponível em: http://www.e-publicacoes.uerj.br/index.php/redp//edicao_02.htm. Acesso em: 12 set. 2010.

32 "A possibilidade de acesso ao juiz tem a função de assegurar uma audiência das razões das partes e a obtenção de uma decisão sobre o fundo da controvérsia. A recusa de julgamento do mérito deve fundar-se em obstáculos determinados por uma correta organização processual, e não em construções fictícias destinadas a esvaziar o direito de acesso ao juiz. No acesso ao juiz está implícita a tutela da coisa julgada. Na sentença de 10 de junho de 1996, no caso Pullar v. Reino Unido, a Corte afirmou que a idéia de coisa julgada, ou seja, o fato de que uma sentença se torne definitiva e dotada de força obrigatória, é um elemento constitutivo da essência do Estado de Direito e do princípio do primado da lei. O acesso ao juiz estende a tutela jurisdicional até a fase executiva das decisões judiciais. O direito do indivíduo de dirigir-se as um tribunal "seria ilusório se a ordem jurídica interna permitisse que uma decisão judiciária definitiva e obrigatória ficasse inoperante em detrimento de uma das partes". A execução de uma sentença "deve considerar-se parte integrante do processo, nos termos do artigo $6^{\circ}$ " (sentença de 28 de julho de 1999, no caso Immob.Saffi v. Itália)". GRECO, Leonardo. Resenha informativa sobre o direito ao processo justo na Convenção Européia e na Convenção Americana dos Direitos do Homem. Op cit, p. 3.

33 A propósito do tema: BEDAQUE, José Roberto dos Santos. Os elementos objetivos da demanda examinados à luz do contraditório. In: TUCCI, José Rogério Cruz e; BEDAQUE, José Roberto dos Santos (Coords.). Causa de pedir e pedido no processo civil: questões polêmicas. São Paulo: Revista dos Tribunais, 2002. GRECO, Leonardo. Garantias fundamentais do processo: o processo justo. Disponível em: <htttp://www.mundojuridico.adv.br/html/artigos/documentos/texto165.htm>. Acesso em: 2 maio 2006. OLIVEIRA JÚNIOR, Zulmar Duarte. Devido Processo Legal: Contraditório (Trinômio Informação, Reação E Consideração) e o Novo CPC, Revista Eletrônica de Direito Processual, Ano 5, $7^{\circ}$ volume - janeiro a junho de 2011, disponível em http://www.e-publicacoes.uerj.br/index.php/redp/. OLIVEIRA, Carlos Alberto Álvaro de. A garantia do contraditório. Mundo Jurídico. Disponível em: http://www.mundojuridico.adv.br. Acesso em: 20 set. 2009. SCHENK, Leonardo Faria. Cognição Sumária: limites impostos pelo contratidório no processo civil, São Paulo: Saraiva, 2013.

34 "Toda a jurisprudência da Corte, tanto em matéria civil como criminal, se desenvolveu em torno de dois eixos: a garantia do contraditório, entendido como expressão das razões das partes, mesmo nas questões meramente processuais; e a paridade de armas entre as partes. A garantia do contraditório oferece a cada uma das partes uma possibilidade razoável de apresentar as próprias razões e provas, em condições de igualdade com o seu adversário. impondo ao julgador o dever de "proceder ao exame efetivo dos meios, dos argumentos e das provas apresentadas pela parte, respeitada a faculdade de apreciar a sua pertinência em relação à decisão" (sentença de 19 de abril de 1994, no caso Van de Hurk v. Países Baixos). Cada uma das partes deve ter o direito de conhecer, de discutir e de contestar os fatos e as provas capazes de influenciar a decisão, pouco importando de onde provenham, até mesmo de outro magistrado ou do Ministério Público, ou 
Revista Eletrônica de Direito Processual - REDP.

Rio de Janeiro. Ano 11. Volume 18. Número 2. Maio a Agosto de 2017

Periódico Quadrimestral da Pós-Graduação Stricto Sensu em Direito Processual da UERJ

Patrono: José Carlos Barbosa Moreira. ISSN 1982-7636. pp. 261-296

www.redp.uerj.br

Por outro lado, a jurisprudência já considerou que não é obrigatória a existência do direito ao duplo grau de jurisdição para o acesso à justiça. Contudo, se o Estado instituir tribunais, eles ficam imperiosamente submetidos a todas as garantias processuais da Convenção e eventuais limitações de acesso a eles precisam ser legítimas à luz da proporcionalidade e do objeto que tutelam.

Com a mesma base, admitem-se restrições à propositura de demandas, desde que sejam razoáveis. Por isso, a mera existência de prazo para propor uma ação cível ou a exigência de caução não violam, por si, o acesso à justiça ${ }^{35}$.

$\mathrm{O}$ processo justo engloba ainda a independência e a imparcialidade do julgador. A independência é verificada pelo afastamento do magistrado em relação a possíveis intimidações de sujeitos titulares de poder dentro da sociedade, influenciando ilicitamente na tomada da decisão. Imparcialidade, por sua vez, é o distanciamento do interesse do juiz em relação às pretensões e resistências deduzidas perante ele.

Por último, ressalte-se que a duração razoável do processo, apesar da fluidez do conceito, é um componente do processo justo. O fato de sua aferição se dar no caso concreto, a partir dos elementos da demanda e do comportamento de todos os envolvidos na relação processual, não impede que a demora habitual seja severamente condenada ${ }^{36}$.

\section{Direitos fundamentais processuais, harmonização do processo e Direito}

\section{Processual Transnacional}

qual venha a ser o efeito real, que tenham sobre o julgamento". GRECO, Leonardo. Resenha informativa sobre o direito ao processo justo na Convenção Européia e na Convenção Americana dos Direitos do Homem. Op cit, p. 5.

35 "O direito de acesso a um tribunal não é absoluto, podendo sofrer limitações. A exigência de efetividade dos direitos humanos não permite que limitações venham a atingir a própria essência do direito de acesso a um tribunal. Limitações são admissíveis se buscam um objetivo legítimo e se existe uma razoável relação de proporcionalidade entre os meios empregados e o objetivo almejado. A fixação de prazos prescricionais para a propositura de uma demanda civil não é considerada lesiva do direito de acesso ao juiz". GRECO, Leonardo. Resenha informativa sobre o direito ao processo justo na Convenção Européia e na Convenção Americana dos Direitos do Homem, op. cit., p. 6.

36 "Com efeito, entendemos que, enquanto o bem da vida não for entregue ao jurisdicionado que reconhecidamente tem razão, não poderá o processualista considerar-se satisfeito, tampouco com o seu ofício cumprido. Se as controvérsias hoje transpõem fronteiras com crescente frequência, devemos nós também monitorar e acompanhar o processo para onde quer que vá. Lavar as mãos e manter-se indiferente ao que sucede após a prolação da sentença no país de origem implica retroceder a fases anteriores da ciência processual, descomprometidas com a efetiva alteração da realidade sensível da parte". HILL, Flávia Pereira. O direito processual transnacional como forma de acesso à justiça no século XXI : os reflexos e desafios da sociedade contemporânea para o direito processual e a concepção de um título executivo transnacional. Tese de Doutorado. Uerj, 2013, p. 111. 
Revista Eletrônica de Direito Processual - REDP.

Rio de Janeiro. Ano 11. Volume 18. Número 2. Maio a Agosto de 2017

Periódico Quadrimestral da Pós-Graduação Stricto Sensu em Direito Processual da UERJ

Patrono: José Carlos Barbosa Moreira. ISSN 1982-7636. pp. 261-296

www.redp.uerj.br

Na segunda metade do século $\mathrm{XX}$, verificou-se o fenômeno intitulado Constitucionalização do Direito ${ }^{37}$, que se espraiou, inclusive, para o Direito Processual ${ }^{38}$. Como consequência, os direitos fundamentais passaram a ocupar uma posição central na interpretação e aplicação das normas processuais.

Elio Fazzalari salienta que, ao longo do século XX, com a evolução dos meios de comunicação e com os fluxos migratórios ao redor do mundo, acelerou-se o processo de conscientização dos indivíduos acerca dos valores sociais em diferentes partes do globo, fazendo com que adquirisse uma feição de transnacionalidade, que deve ser enfrentada de forma sistemática e coordenada ${ }^{39}$.

Passou-se a perquirir a noção de processo justo e equitativo, que precisaria passar, necessariamente, pela observância das garantias de acesso à justiça, isonomia, efetividade, devido processo legal, contraditório, ampla defesa e duração razoável do processo.

Serge Guinchard destaca o surgimento de uma "dimensão mundial do processo", a partir da busca pela valorização dos direitos fundamentais processuais em diferentes países. O Direito Processual interno passa a ser irrigado por standards comuns oriundos de fontes internacionais e constitucionais ${ }^{40}$.

${ }^{37}$ Sergue Guinchard considera a constitucionalização do Direito uma verdadeira "revolução jurídica". GUINCHARD, Serge (Org.). CHAINAIS, Cécile. DELICOSTOPOULOS, Constantin S. DELICOSTOPOULOS, Ioannis S. DOUCHY-OUDOT, Mélina. FERRAND, Frédérique. LAGARDE, Xavier. MAGNIER, Véronique. FABRI, Hélène Ruiz. SINOPOLI, Laurence. SOREL, Jean-Marc. Droit Processuel. Droits fondamentaux du process. 6. ed. Paris: Dalloz. 2011, p. 365.

38 'On assiste actuellement, sous l'influence conjuguée des normes supra-nationales et des auteurs tant français qu'étrangers qui s'intéressent à ce mouvement d'internationalisation et de constitutionalisation des procédures (et qui le conceptualisent), à la constitutionalisation des procédures (et qui le conceptualisent), à la création progressive, mais inéluctable, d'une science de la procédure, d'un nouveau droit processuel envisagé comme un droit commun à tous les types de contentieux". GUINCHARD, Serge (Org.). Op. cit, p. 32.

39 “Inoltre, quello dell'economia, se è l'aspetto più vistoso della realtà transnazionale, non è il più esteso esso riguarda determinate aree geografiche - né il solo. Nel corso del Novecento, l'accelerazione degli eventi e l'aumento esponenziale delle conoscenze e dei valori sociali (l'una e l'altra contrassegni del secolo: non acaso esso è sembrato, ed è stato definito, "breve ») hanno indotto profonde modifiche in tutte le componenti della cultura, intesa come civiltà. È ovvio che tali cambiamenti, suscitati nella parte più progredita del mondo, non hanno fatto presa in ogni dove, né alla stessa maniera; però hanno di certo dimostrato capacità di vasta diffusione, cioé, appunto, una intrinseca transnazionalità. Alla quale contribuiscono anche i flussi migratori (che da sempre la storia conosce come veicolo di trasformazione e integrazione culturali). Spicca, su tutte, una mondializzazione più avanzata e (quasi) completa: quella prodotta dalla pervasività dei mezzi di comunicazione (dagli aerei supersonici ai satelliti, ai computers). I problemi dell'umanità intera, delle sue frazioni, dei suoi strati, sono dinnanzi a noi e chiedono di essere affrontati." FAZZALARI, Elio. "Mondializzazione', politica, diritto". In Rivista Trimestrale di Diritto e Procedura Civile. Milão: Giuffrè. 2000. pp. 682-683.

40 "En effet, le droit processuel d'aujourd'hui dépasse la simple comparaison des trois contentieux et se trouve irrigué par des standards communs à tous les procès, nationaux et internationaux, peu important qu'ils relèvent de la matière civile ou de la matière pénale, standards provenant de sources internationales, pour l'essentiel européennes, mais aussi de sources constitutionnelles. Le droit processuel a changé de dimension; 
Revista Eletrônica de Direito Processual - REDP.

Rio de Janeiro. Ano 11. Volume 18. Número 2. Maio a Agosto de 2017

Periódico Quadrimestral da Pós-Graduação Stricto Sensu em Direito Processual da UERJ

Patrono: José Carlos Barbosa Moreira. ISSN 1982-7636. pp. 261-296

www.redp.uerj.br

Assim, o conteúdo contemporâneo do Direito Processual não negligencia as grandes teorias clássicas do processo (ação, jurisdição e do processo), mas as engloba e aprimora, tendo como principal premissa as garantias fundamentais processuais.

A celebração de tratados internacionais agasalhando tais garantias ${ }^{41}$, aliada à jurisprudência coerente e harmônica dos tribunais internacionais, dentre os quais se destacam a Corte Europeia de Direitos do Homem e a Corte Interamericana de Direitos do Homem, contribuíram decisivamente para a sua valorização em diferentes países e para a atribuição de contornos similares às garantias fundamentais.

Sendo assim, países de diversos continentes passaram a interpretar suas leis processuais internas e a elaborar novas normas processuais à luz das garantias fundamentais do processo. Isso fez com que houvesse uma natural aproximação entre os sistemas jurídico-processuais dos países. A esse fenômeno intitulou-se harmonização do processo.

Esse fenômeno vem se desenvolvendo e progredindo, segundo Nicolò Trocker, apesar de encontrar um importante entrave: o orgulho e o apego dos Estados nacionais a seus respectivos sistemas jurídicos internos e o propósito de reafirmarem a jurisdição de seus tribunais nacionais contra o que considerariam "ingerência estrangeira" e que, em verdade, consiste na cooperação jurídica internacional. O autor sustenta que a aproximação

il n'est plus le droit des procéduriers qui réfléchissent sur leur discipline en comparant les divers contentieux dans leur pure technique procédurale, mais le droit de ceux qui s'interessent aux sources communes d'inspiration de tous les contentieux, à leurs fondements, aux principes de droit naturel qui s'imposent dans la conduite de tous les procès, Le droit processuel, dans une approche plus moderne, qui complète la première sans l'exclure totalement (mais en la marginalisant), c'est le droit du procès, de tous les procès, c'est l'étude des drois fondamentaux du procès." GUINCHARD, Serge (Org.). Op. cit., p. 4.

41 "Les mutations du droit du procès à l'époque contemporaine traduisent et induisent une nouvelle conception du droit processuel, complètement attrait, par les instruments internationaux de protection des droits de l'homme, à la garantie des libertés et droits fondamentaux (...) Cette importance croissante de l'attraction de la procédure par les droits fondamentaux garantis essentiellement par les instruments internationaux des droits de l'homme tient à trois facteurs. Ils tiennent: - d'une part, à l'applicabilité directe de ces instruments; - d'autre part, à l'existence d'un concept coherent, qui leur est d'ailleurs commun, celui de process equitable; - enfin, à l'utilisation, par les organs de contrôle de ces instruments internationaux, et notamment par la Cour EDH, de méthodes originales pour assurer l'effectivité des droits fondamentaux et de la garantie d'un process equitable. S'agissant du deuxième facteur, il faut souligner que l'attraction de la procédure par les droits fondamentaux et à la garantie de ceux-ci, participe d'un mouvement plus général d'internationalisation du droit processuel. Le centre de la question se ramène à une seule notion, qui s'exrpime en deux mots seulement, 'procès équitable'. Jamais si peu de mots n'ont autant bouleversé le droit du procès. L'expression n'est pas spécifique au droit européen, même si elle est au coeur de l'article 6 de la Convention EDH.” GUINCHARD, Serge (Org). Op. cit. p. 5 e pp. 94-95. 
Revista Eletrônica de Direito Processual - REDP.

Rio de Janeiro. Ano 11. Volume 18. Número 2. Maio a Agosto de 2017

Periódico Quadrimestral da Pós-Graduação Stricto Sensu em Direito Processual da UERJ

Patrono: José Carlos Barbosa Moreira. ISSN 1982-7636. pp. 261-296

www.redp.uerj.br

entre os sistemas jurídico-processuais facilita a solução do crescente volume de controvérsias transnacionais que são submetidas aos tribunais nacionais ${ }^{42}$.

Os direitos fundamentais mudaram, segundo Serge Guinchard, a técnica processual, fazendo emergir um "direito processual comum", que sobrepaira às divergências pontuais entre os sistemas processuais nacionais, configurando "fontes supra legislativas" de Direito Processual $^{43}$.

Michele Taruffo destaca que, especialmente nas últimas décadas do século XX, emergiu uma tendência à superação do modelo de Estado-nação e à aproximação entre os sistemas processuais dos diferentes países ao redor do mundo ${ }^{44}$.

Taruffo esclarece ainda que a sociedade globalizada passa a submeter aos tribunais dos diferentes países do mundo demandas semelhantes e, por conseguinte, os desafios trazidos ao Direito Processual se mostram essencialmente os mesmos ao redor do globo. Isso cria uma cultura jurídica comum, a partir do que o autor intitula "universalização dos princípios fundamentais da justiça civil" ${ }^{45}$.

\footnotetext{
${ }^{42}$ TROCKER, Nicolò. La formazione del Diritto Processuale Europeo. Turim: G. Giappichelli Editore. 2011, p. 349.

43 “C'est ce volet 'protection des droits fondamentaux' qui a aujourd'hui considérablement transformé la technique procedural, qu'elle quelle soit; ce volet c'est le nouveau droit processuel ainsi envisagé comme la science de la procédure et non plus seulement comme le 'droit de la procédure'. Progressivement, tout un droit commum du procès se construit sous nos yeux, par l'impulsion que donnent à tous les contentieux, audelà de leurs divergences congénitales, les sources supra-législatives de ce droit." GUINCHARD, Serge (Org.). Op. cit, p. 5.

44 "Principalmente a partire dagli anni che seguono la fine del secondo conflitto mondiale, ma con intensità sempre maggiore nei decenni successivi sino ad un crescendo particolarmente intenso negli ultimi de cenni del '900, emergono tendenze di varia natura che per un verso segnano punti rilevanti di crisi del modello esclusivo dello Stato-nazione, e per altro verso indicano direzioni di superamento in senso positivo di questo modello. Tentando di riunire in una formulazione complessiva fenomeni estremamente complessi e molto diversificati, si potrebbe parlare di tendenze alla configurazione di aree economiche, politiche e culturali di rilevante ampiezza, nelle quali si manifestano anche spinte significative all'armonizzazione del diritto in generale, ed in particolare alla convergenza della disciplina processuale su punti di riferimento relativamente omogenei." TARUFFO, Michele. "Note sulla dimensione transnazionale delle controversie civili". In Rivista Trimestrale di Diritto e Procedura Civile. Milão: Giuffrè. 2001. Versão eletrônica anual. p. 1060.

45 “'(...) Una ragione di ciò è la percezione del fatto che i problemi fondamentali dell'amministrazione della giustizia sono sostanzialmente gli stessi in tutti gli ordinamenti giuridici moderni. Le soluzioni che i diritti nazionali forniscono per questi problemi sono diverse, e le differenze appaiono più rilevanti quando si prendono in considerazione specifiche norme processuali (dato che, come si dice, il diavolo è nei dettagli). Tuttavia, se si considerano le varie soluzioni normative come equivalenti funzionali — ossia: come risposte diverse alle stesse domande fondamentali - si può individuare un comune terreno di base. Un altro fattore che favorisce la costruzione di una cultura processuale comune si può definire come l'universalismo dei princìpi fondamentali della giustizia civile. Si tratta di un esempio particolare del «passionate belief in fundamental rights » che - secondo Friedman è uno degli aspetti più importanti della cultura giuridica moderna. I giuristi di molti paesi e di diverse culture prendono coscienza del significato universale di princìpi come l'indipendenza della magistratura, l'imparzialità del giudice, la possibilità effettiva di far valere i propri diritti, la garanzia della difesa e di un processo corretto, e così via. I valori che stanno alla base di questi princìpi processuali sono ormai patrimonio comune delle culture giuridiche e politiche di tutti gli ordinamenti
} 
Revista Eletrônica de Direito Processual - REDP.

Rio de Janeiro. Ano 11. Volume 18. Número 2. Maio a Agosto de 2017

Periódico Quadrimestral da Pós-Graduação Stricto Sensu em Direito Processual da UERJ

Patrono: José Carlos Barbosa Moreira. ISSN 1982-7636. pp. 261-296

www.redp.uerj.br

Taruffo salienta, ainda, que a realização de estudos e pesquisas envolvendo juristas de diferentes nacionalidades contribui significativamente para a formação de um Direito Processual mais harmônico ao redor do mundo e atende às exigências da chamada "ordem jurídica global”, que cobra por respostas céleres ${ }^{46}$.

Elio Fazzalari sustenta igualmente que o processo de transição rumo a um "direito comum", ou à harmonização dos sistemas jurídicos, não depende exclusivamente de medidas cogentes impostas pelos Estados e organismos internacionais, mas é implementado principalmente a partir da experiência concreta, mediante a atuação dos diferentes operadores do Direito ao interpretar e aplicar as normas internas ${ }^{47}$.

Não se trata de uniformizar o Direito Processual interno dos países, impondo-lhes normas idênticas, mas de uma paulatina aproximação quanto à sua essência, com vistas a traduzir e aplicar adequadamente as garantias fundamentais do processo $^{48}$. Ainda que

moderni, benché essi trovino realizzazione effettiva in modi molto diversi. Questi valori e questi princìpi sono dunque la base per una possibile cultura generale della giustizia civile”. TARUFFO, Michele. "Dimensioni transculturali della giustizia civile". Rivista Trimestrale di Diritto e Procedura Civile. Milão: Giuffrè. 2000. Versão eletrônica anual, pp. 1083-1084.

46 "Il problema si apre, e richiede nuove soluzioni, poiché nuove tendenze e nuove esigenze emergono nel contesto dell'ordine giuridico globalizzato. L'esigenza che si manifesta in modo più evidente è nel senso dell'unità o uniformità della disciplina processuale applicabile alle controversie transnazionali. Da un lato, la crescente omogeneizzazione del diritto globale sostanziale, e la gestione delle controversie da parte di studi legali che operano in dimensione sovranazionale o addirittura mondiale, entrano in contraddizione con situazioni in cui la controversia viene trattata e decisa secondo norme processuali 'locali'. Dall'altro lato, il superamento dei paradigmi nazionali che caratterizza la controversia transnazionale accentua questa contraddizione, rendendo sempre più ingiustificata l'applicazione diversificata di regole procedurali nazionali a situazioni che tendono ad essere regolate da norme e criteri uniformi sotto il profilo sostanziale. Bisogna poi considerare che l'esigenza di rapidità ed efficienza della soluzione delle controversie diventa particolarmente forte e generalizzata nell'ambito dell'economia globale, improntata all'estrema rapidità di tutti gli scambi, sicché le notevoli differenze esistenti tra i singoli ordinamenti — che riguardano in particolare la durata del processo e l'attuazione effettiva della decisione - diventano sempre meno giustificabili e tollerabili." TARUFFO, Michele. "Note sulla dimensione transnazionale delle controversie civili”. In Rivista Trimestrale di Diritto e Procedura Civile. Milão: Giuffrè. 2001. Versão eletrônica anual. p. 1065 .

${ }^{47}$ FAZZALARI, Elio. “'Mondializzazione', politica, diritto”. In Rivista Trimestrale di Diritto e Procedura Civile. Op. cit. pp. 689-691.

48 'In the authors opinion, the question of significant procedural 'divergence' and 'contrasting techniques' raises the more general issue whether it is desirable to maintain competition between various bodies to fashion effective and modern principles and rules of civil procedure. 'International uniformity on all points of procedural details is an unattractive goal, but agreement on fundamental values and doctrines is desirable'. This was the consensus emerging at the discussion of the (then) draft Principles and Rules held at the British Institute for International and Comparative Law in May 2002 by leading English judges and commentators. (...) 'Plurality of procedure encourages experimentation and promotes evolutionary progress. Jurisdictional competition could (...) lead to improvement in dispute resolution. It might, therefore, be better to direct the efforts in this area not so much towards an unified procedural system for transnational cases but towards establishment of general normative standards that allow for considerable variations. Community of general standards would facilitate easier mutual recognition of judgments and (...) enable different jurisdictions to find their own way of providing adjudication that is effective and attractive (...)'." ANDREWS, Neil. The 
Revista Eletrônica de Direito Processual - REDP.

Rio de Janeiro. Ano 11. Volume 18. Número 2. Maio a Agosto de 2017

Periódico Quadrimestral da Pós-Graduação Stricto Sensu em Direito Processual da UERJ

Patrono: José Carlos Barbosa Moreira. ISSN 1982-7636. pp. 261-296

www.redp.uerj.br

mantendo instrumentos com características ou dinâmicas pontualmente diversas, os

Estados passaram a se preocupar com que seus instrumentos processuais representem a máxima aplicação das garantias fundamentais.

Serge Guinchard ressalta que as garantias fundamentais do processo emergem como um "fundo comum universal do processo", criando um "modelo universal do processo justo" ${ }^{\prime 4}$.

Paolo Biavati, por seu turno, considera inexorável a tendência à harmonização e salienta que um dos principais efeitos da globalização consiste na atenuação da relação entre pessoa e dado território, gerando, como consequência, o favorecimento de regras homogêneas e a mitigação do liame entre território, lei aplicável e jurisdição competente ${ }^{50}$. $\mathrm{O}$ autor constata a tendência à "fungibilidade entre os ordenamentos jurídicoprocessuais" $"$.

modern procedural synthesis: the American Law Institute and Unidroit's Principles and Rules of Transnational Civil Procedure. Revista de Processo. Vol. 164. Ano 2008. pp. 118-119.

49 "Les trois métamorphoses du droit du procès. Au final, trois axes nous semblent devoir caractériser les métamorphoses contemporaines du droit du procès: En premier lieu, sous l'influence prépondérante des instruments internationaux des droits de l'homme (que nous préférons designer par l'expression de libertés et drois fondamentaux), la procédure, comme l'ordre juridique en général, se trouve placée aujourd'hui sous l'emprise croissante des drois fondamentaux, à la garantie desquels, d'ailleurs, elle participe, à tel point que l'on peut désormais parler de droits fondamentaux du procès (les fameux 'drois de procédure' évoqués aux Conseils européens de Cologne et Tampere au moment de l'élaboration de ce qui allait devenir la Charte des drois fondamentaux de l'Union européenne) et qu'il existe un véritable droit substantiel à um procès équitable conforme aux exigences d'un État démocratique, c'est-à-dire aux garanties fondamentales d'une bonne justice. L'humanisme processuel l'emporte sur le légalisme procédural, même si certains accompagnent cette évolution de réserves fondées sur l'autonomie processuelle. En deuxième lieu, les modèles de procès apparaissent, empruntant à plusiers traditions juridiques, mais avec un fonds commun universel, celui qui correspond, précisément, aux garanties fondamentales d'une bonne justice; si un rapprochement s'opère entre les procédures accusatoire et inquisitoire, c'est toujours dans le respect de ce modèle universel, celui du procès équitable. La modélisation des procès par la mondialisation des procédures constitue ce deuxième axe de ce qui a changé et change encore dans notre procédure, au début du troisième millénaire. Enfin, la procédure elle-même, dans ce qu'elle a de plus technique, se renouvelle, avec une intensité plus ou moins forte selon le type de contentieux et selon le calendrier des réformes gouvernementales, donc sous la dépendance des aléas des majorités politiques, (...). Cette évolution de la technique des procès laisse entrevoir un point commun, une ligne force, l'émergence de nouveaux principes directeurs du process qui traduisent les besoins de davantage de dialogue pour assurer l'écoute de l'Autre, de loyauté pour concrétiser la confiance légitime dans l'adversaire et dans le juge, mais aussi de célérité, forme moderne du besoin de proximité (le temps gagne sur l'espace); les rôles respectifs du juge, des parties, du ministère public, s'en trouvent modifiés et en ce sens on peut parler de principes structurants. Ces changements, ces métamorphoses des procédures et du droit du procès, induisent une nouvelle conception du droit processuel qui devient ainsi le droit commun du procès, de tous les procès, sous l'angle de la protection des libertés et drois fondamentaux." GUINCHARD, Serge. Op. Cit. pp. 08-09.

${ }^{50}$ BIAVATI, Paolo. "Deroghe alla giurisdizione statuale e fungibilità dei sistemi giudiziari". In Rivista Trimestrale di Diritto e Procedura Civile. Ano 2009. pp. 524-525.

51 "Pienamente coerente con il disegno finora descritto, che facilita la volontà delle parti di scegliere la giurisdizione ritenuta più adatta, per garantire una migliore applicazione della legge prescelta per governare il rapporto, è una struttura dei singoli sistemi giudiziari che ne faciliti la fungibilità. (...) Il messaggio della Corte costituzionale è duplice: da un lato, evitare rigide chiusure e collegamenti impropri fra le garanzie 
Revista Eletrônica de Direito Processual - REDP.

Rio de Janeiro. Ano 11. Volume 18. Número 2. Maio a Agosto de 2017

Periódico Quadrimestral da Pós-Graduação Stricto Sensu em Direito Processual da UERJ

Patrono: José Carlos Barbosa Moreira. ISSN 1982-7636. pp. 261-296

www.redp.uerj.br

Um esforço nesse sentido consiste na elaboração dos Princípios de Direito

Processual Transnacional elaborados pelo Unidroit e pelo American Law Institute, que trazem parâmetros de interpretação e aplicação das normas processuais internas, à luz dos princípios fundamentais processuais e com vistas a fomentar a cooperação jurídica internacional e solucionar as controvérsias transnacionais ${ }^{52} 2_{-} 53_{-} 54$.

interne e le diverse opzioni dei singoli ordinamenti, con cui l'Italia si pone in relazione e, dall'altro lato, avere la consapevolezza che la fungibilità non è un dato acquisito, ma una tendenza. (...) Ciò che rende diseguali i sistemi giudiziari, in Europa e a maggior ragione fuori Europa, non sono tanto le procedure, quanto gli aspetti organizzativi: i tempi, i costi, le modalita` di esercizio dell'attivita` forense. Ritorno una volta anco`ra sulla chiara tendenza a concepire la giurisdizione, più che come un potere, come un servizio volto a risolvere controversie, rispetto al quale il corretto ed efficace funzionamento è più importante delle specifiche regole di procedura. Mi piace paragonare questa attesa di efficienza nei confronti dei sistemi giurisdizionali a ciò che un viaggiatore si attende da un aeroporto: puntualità, indicazioni e servizi, declinati secondo un linguaggio comune ad ogni parte del mondo. In realtà, l'armonizzazione del diritto processuale, auspicata in dottrina a livello internazionale e perseguita normativamente dal diritto dell'Unione europea, in base all'art. 65 tr. Ce, non è un frutto a portata di mano. La situazione attuale è quella di una fase intermedia, con profili normativi in cui si segnano importanti passi avanti e altri settori che appaiono ancora lontani da un accettabile standard comune. (...) Insomma, molta strada va ancora percorsa, ma è innegabile che una base comune esiste e che l'equivalenza fra le giurisdizioni è un'affermazione sempre meno falsa." BIAVATI, Paolo. Op. Cit. pp. 537-539.

${ }^{52}$ AMERICAN LAW INSTITUTE. UNIDROIT.Principles of Transnational Civil Procedure. Disponível no endereço eletrônico: http://www.unidroit.org/english/principles/civilprocedure/ali-unidroitprinciples-e.pdf Consulta realizada em 12/12/2015.

53 "Si tratterebbe, in altri termini, di uniformare il trattamento processuale di queste controversie facendo in modo che tutti i giudici dei vari ordinamenti applichino lo stesso corpus di regole fondamentali quando debbono decidere controversie transnazionali. Va in questa direzione un progetto che già da qualche anno è in corso di elaborazione sotto gli auspici dell'American Law Institute - e che ha ricevuto anche l'adesione di Unidroit per quanto attiene alla formulazione di principi processuali comuni - il cui obbiettivo e` appunto la redazione di un insieme di regole processuali potenzialmente applicabili da qualunque giudice nazionale nel caso in cui debbano essere risolte controversie transnazionali. Questo progetto è ancora in corso di svolgimento, e non è possibile riassumerne qui i contenuti ed il grado di elaborazione. Si può tuttavia osservare che, benché numerosi problemi rimangano ancora aperti, esso sembra capace di produrre esiti positivi nell'individuazione di una possibile disciplina processuale almeno parzialmente comune per le controversie transnazionali. Questa disciplina potrebbe rappresentare un importante fattore di unificazione poiché potrebbe essere materia di direttive o di model rules emanate da organi internazionali, o potrebbe essere adottata da quei legislatori nazionali che volessero integrare i loro sistemi processuali in un contesto armonizzato di regole per le controversie transnazionali. D'altronde non si può neppure escludere a priori che, qualora prendessero corpo i progetti di Stato mondiale di cui si è fatto cenno in precedenza, queste regole comuni possano rappresentare la base per una disciplina processuale uniforme." TARUFFO, Michele. "Note sulla dimensione transnazionale delle controversie civili". In Rivista Trimestrale di Diritto e Procedura Civile. Milão: Giuffrè. 2001. Versão eletrônica anual p. 1069.

54 "The Principles offer a balanced distillation of best practice of civil justice, especially in the sphere of transnational commercial litigation. They are not restricted to the largerly uncontroversial 'high terrain' of constitutional guarantees of due process. The project was skillfully pitched at the difficult mid-point between uncontroversial procedural axiom and the fine texture of national codes. (...) as the preamble to the Principles states, the main focus of the drafting party was to agree 'standards for adjudication of transnational disputes'. But the preamble adds that the Principles might be 'equally appropriate for resolution of most kinds of civil disputes' and they might form 'the basis for future initiatives in reforming civil procedure'." ANDREWS, Neil. The modern procedural synthesis: the American Law Institute and Unidroit's Principles and Rules of Transnational Civil Procedure. Revista de Processo. Vol. 164. Ano 2008, p. 113. 
Revista Eletrônica de Direito Processual - REDP.

Rio de Janeiro. Ano 11. Volume 18. Número 2. Maio a Agosto de 2017

Periódico Quadrimestral da Pós-Graduação Stricto Sensu em Direito Processual da UERJ

Patrono: José Carlos Barbosa Moreira. ISSN 1982-7636. pp. 261-296

www.redp.uerj.br

Neil Andrews destaca a importância dos Princípios de ALI/Unidroit para o Direito Processual contemporâneo, sustentando que influenciarão, de alguma forma, todos os sistemas processuais do mundo. Para o autor, alguns Estados adotarão tais princípios sem qualquer modificação, outros os adaptarão às suas necessidades e, mesmo entre os países que optem por não os adotar imediatamente, decerto os princípios consistirão em valioso parâmetro de orientação para futuras mudanças legislativas ${ }^{55}$.

Andrews pondera que a uniformidade internacional do Direito Processual, mesmo quanto aos detalhes procedimentais, não é desejável. Deve-se buscar um acordo quanto aos valores fundamentais do processo. $\mathrm{O}$ autor acredita que os Princípios de ALI/Unidroit orientarão os trabalhos dos juristas e influenciarão a atuação dos responsáveis pelas políticas públicas ${ }^{56}$.

Deve-se registrar, ainda, a elaboração, pelo Instituto Ibero-americano de Direito Processual, dos Códigos Modelo de Direito Processual Civil e Penal, de Processo Coletivo e de Cooperação Interjurisdicional ${ }^{57}$, que almejam inspirar e nortear a edição de normas pelos países ibero-americanos e, assim, contribuir para a harmonização entre os ordenamentos processuais.

As Cortes Internacionais também exercem papel relevante, na medida em que trazem parâmetros concretos de aplicação das garantias fundamentais e seus julgados servem de exemplo tanto para a atuação dos Estados quanto para a elaboração de novas leis processuais. E assim, pouco a pouco, vemos que o Direito Processual dos diferentes países passa a oferecer características essenciais cada vez mais próximas em sua essência.

Esse progresso somente vem acontecendo em razão do crescimento do volume de controvérsias transnacionais. Tanto os tribunais internacionais são reiteradamente chamados a se manifestar, quanto os tribunais e autoridades nacionais são igualmente instados a solucionar tais litígios em observância às garantias fundamentais e, mais do que isso, a organizar um sistema processual estruturado e apto a solucioná-los adequadamente.

\footnotetext{
55 ANDREWS, Neil. "Embracing the noble quest for Transnational Procedural Principles". In ANDENAS, Mads. NAZZINI, Renato. ANDREWS, Neil. (Orgs.) The Future of Transnational Civil Litigation. English Responses to que ALI/UNIDROIT. Draft Principles and Rules of Transnational Civil Procedure. Londres: The British Institute of International and Comparative Law. 2006. pp. 21-22.

56 ANDREWS, Neil. "The modern procedural synthesis: the American Law Institute and Unidroit's 'Principles and rules of transnational civil procedure'”. In Revista de Processo, ano 33, n. 164, out 2008, pp. 118-119.

57 INSTITUTO IBEROAMERICANO DE DIREITO PROCESSUAL. Códigos Modelo disponíveis no endereço eletrônico: http://www.direitoprocessual.org.br/index.php?codigos-modelo-4 Consulta realizada em 01/04/2016.
} 
Revista Eletrônica de Direito Processual - REDP.

Rio de Janeiro. Ano 11. Volume 18. Número 2. Maio a Agosto de 2017

Periódico Quadrimestral da Pós-Graduação Stricto Sensu em Direito Processual da UERJ

Patrono: José Carlos Barbosa Moreira. ISSN 1982-7636. pp. 261-296

www.redp.uerj.br

Serge Guinchard ${ }^{58}$ reconhece que a multiplicação de controvérsias transnacionais foi um dos principais fatores que conduziram os Estados a colocar na ordem do dia a reflexão em torno da aplicação das garantias fundamentais do processo a esses casos, vencendo as resistências iniciais à noção de um Direito Processual Transnacional e mundializado.

Não basta improvisar casuisticamente adaptações ao modelo processual essencialmente interno, cunhado séculos atrás, sendo necessário reestruturá-lo segundo a nova conformação social.

Fala-se, assim, em Direito Processual Transnacional, voltado a oferecer instrumentos processuais aptos a solucionar as controvérsias que envolvam elementos concernentes a mais de um Estado, garantindo aos jurisdicionados soluções que atendam às garantias de isonomia, acesso à justiça, efetividade, contraditório, ampla defesa e duração razoável do processo.

Não se deve confundir controvérsia transnacional com controvérsia internacional.

A controvérsia internacional baseia-se, assim como as controvérsias internas, na noção de Estado-nação, referindo-se ao litígio que apresenta, acidentalmente, um elemento relacionado a outro Estado-nação. Sob essa ótica, seria aplicável às controvérsias internacionais em linhas gerais o mesmo sistema processual criado para solucionar as controvérsias internas.

A controvérsia transnacional, por seu turno, não se baseia na noção de Estadonação e, por conseguinte, não pode ser considerada uma mera exceção à controvérsia interna. Ela ostenta características peculiares, sendo produto da nova configuração da sociedade atual, que compartilha hábitos e informações cada vez mais parecidos e que se

58 "Il y a quelque paradoxe à parler de sources internationals et notamment onusiennes du droit processuel, alors que la discipline est essentiellement nationale, pour ne pas dire 'nationaliste', puisque son objet principal est de régir la conduite d'un procès devant une juridiction étatique et que la souveraineté des États se manifeste fortement à travers l'activité de leurs juges. La procédure, quelle qu'elle soit, s'accomoderait mal, a priori, de règles internationales, d'origine supranationale. (...) Malgré ces éléments de résistance à l'insertion du droit processuel dans un cadre international, cette discipline s'internationalise sou l'effet complémentaire de deux facteurs: - d'une part, le développement des relations internationales entre les sujets de droit qui multiplie les causes de survenance de litiges internationaux. Nous dirons quelques mots de ces sources du droit processuel international, en laissant de côté cependant ce qui concerne les juridictions internationales; - d'autre part, et indépendamment de tout litige international, les États acceptant, généralement par la conclusion de conventions internationals multilaterals, de respecter, dans la conduit des procedures se déroulant au sein de leur ordre juridique, certains principes ou standards, que l'on peut qualifier de fondamentaux, par analogie et évocation des droits et libertés sembablement qualifiés; certains auraient parlé autrefois de principes 'naturels'. Ce sont ces conventions qui constituent la véritable source internationale du droit processuel au sens de droit commun du process." GUINCHARD, Serge (Org.). Op. cit, p. 103. 
Revista Eletrônica de Direito Processual - REDP.

Rio de Janeiro. Ano 11. Volume 18. Número 2. Maio a Agosto de 2017

Periódico Quadrimestral da Pós-Graduação Stricto Sensu em Direito Processual da UERJ

Patrono: José Carlos Barbosa Moreira. ISSN 1982-7636. pp. 261-296

www.redp.uerj.br

afasta, assim, do paradigma nacional. Tal espécie de controvérsia vai muito além da presença de um elemento circunstancial de estraneidade, podendo abarcar desdobramentos em diversos Estados ${ }^{59}$.

Dito isso, garantir o acesso à justiça aos jurisdicionados envolvidos em litígios transnacionais significa lhes oferecer instrumentos processuais aptos a solucioná-los adequadamente, com celeridade e a custos razoáveis, sob pena de haver quebra de isonomia. Ao jurisdicionado envolvido em litígios transnacionais não podem ser colocados obstáculos ilegítimos, que inviabilizem, na prática, a sua solução.

A constitucionalização do Direito Processual aliada à valorização das garantias fundamentais processuais, que se operam em diferentes países do mundo, fazem emergir a exigência de que, ao jurisdicionado envolvido em litígios transnacionais, seja oferecido o mesmo grau protetivo de acesso à justiça, as mesmas chances de ver dirimida a sua causa, ainda que, para tanto, seja necessária a participação de mais de um Estado.

Oferecer ao jurisdicionado inserido em uma sociedade global instrumentos cunhados séculos atrás para a solução de controvérsias internas corresponde, em última análise, à negativa de acesso à justiça. $\mathrm{O}$ oferecimento de instrumentos processuais inadequados e obsoletos representa a imposição de obstáculos ilegítimos à solução dos litígios transnacionais, com o dispêndio de tempo e recursos irrazoáveis.

Para que seja efetivamente garantida ao jurisdicionado envolvido em litígios transnacionais a observância do acesso à justiça, da isonomia e da duração razoável do processo, faz-se necessário repensar o Direito Processual contemporâneo, de modo a adequar os instrumentos processuais tradicionais e criar novos mecanismos voltados a atender as especificidades da sociedade globalizada.

Por outro lado, o fenômeno da harmonização entre os sistemas jurídico-processuais dos Estados vem contribuir para a solução dos litígios transnacionais e para a concretização das garantias processuais nos litígios transnacionais, pois a similitude entre os sistemas facilita o reconhecimento e o cumprimento de decisões judiciais estrangeiras, permitindo que os tribunais nacionais se sintam mais confortáveis e seguros ao adotar medidas de fomento da cooperação jurídica internacional.

\footnotetext{
${ }^{59}$ HILL, Flávia Pereira. O Direito Processual Transnacional como forma de acesso à justiça no século XXI. Op. Cit. pp. 60-71.
} 
Revista Eletrônica de Direito Processual - REDP.

Rio de Janeiro. Ano 11. Volume 18. Número 2. Maio a Agosto de 2017

Periódico Quadrimestral da Pós-Graduação Stricto Sensu em Direito Processual da UERJ

Patrono: José Carlos Barbosa Moreira. ISSN 1982-7636. pp. 261-296

www.redp.uerj.br

\section{Direito Processual Transnacional e o conceito de "processo justo"}

A concepção das garantias fundamentais processuais moldou-se em função do conceito de "processo justo".

A exigência do processo justo foi expressa, pela primeira vez, no artigo 10 da Declaração Universal dos Direitos do Homem de 10/12/1948. O artigo 10 se mantém como texto de referência, com um valor moral. Ele inspirou, desde então, os demais instrumentos internacionais.

$\mathrm{O}$ artigo $14, \S 1^{\circ}$, do Pacto Internacional relativo aos direitos civis e políticos, de 19/12/1966, que ratifica a exigência de um processo justo, ostenta grande importância, por ser autoexecutório e ser dotado de um órgão de controle, o Comitê de Direitos do Homem da ONU, que elaborou jurisprudência marcadamente protetiva. Toda a jurisprudência do Comitê foi construída de modo a tornar o direito a um processo justo um verdadeiro direito substancial.

No tocante à Europa, tem particular relevo, a partir da entrada em vigor do Tratado de Amsterdã, a jurisprudência da Corte Europeia de Justiça (Corte de Luxemburgo) em matéria de direitos fundamentais e quanto ao controle exercido da observância da Carta de direitos fundamentais da União Europeia, editada em Nice, em 18/12/2000 ${ }^{60}$.

O artigo 47 da referida Carta garante o julgamento de forma equitativa, respeitando-se o contraditório, a publicidade do processo, a independência e a imparcialidade do juiz, o juiz natural e a duração razoável do processo.

$\mathrm{O}$ artigo $6^{\circ}, \S 1^{\circ}$ da Convenção Europeia de Direitos do Homem é considerado a salvaguarda dos direitos fundamentais processuais e baliza a atuação dos Estados europeus signatários e de seus tribunais. Incumbe à Corte Europeia de Direitos do Homem (Corte de Estrasburgo) zelar pela correta aplicação da referida norma, sendo responsável pela elaboração de jurisprudência precursora e vanguardista, que inspira tribunais de diferentes partes do mundo.

Na Itália, a Lei Constitucional Italiana n. 2, de 23/11/1999, inseriu no artigo 111 da Constituição, cinco alíneas que a colocam em conformidade com as normas convencionais europeias, referindo-se a justo processo regido pela Lei, ao princípio do contraditório, da igualdade de armas, do juiz terceiro e imparcial e da duração razoável do processo.

${ }^{60}$ UNIÃO EUROPEIA. Carta de direitos fundamentais da União Europeia. Disponível, em português, no endereço eletrônico: http://www.europarl.europa.eu/charter/pdf/text_pt.pdf Consulta realizada em 01/04/2016. 
Revista Eletrônica de Direito Processual - REDP.

Rio de Janeiro. Ano 11. Volume 18. Número 2. Maio a Agosto de 2017

Periódico Quadrimestral da Pós-Graduação Stricto Sensu em Direito Processual da UERJ

Patrono: José Carlos Barbosa Moreira. ISSN 1982-7636. pp. 261-296

www.redp.uerj.br

O Brasil, por seu turno, é signatário da Convenção Interamericana de Direitos Humanos (Pacto de São José da Costa Rica, de 22/11/1969) que, preconiza, no artigo $8^{\circ}$, os princípios fundamentais do processo justo, notadamente a publicidade, a imparcialidade e a independência do juiz, o juiz natural e a duração razoável do processo ${ }^{61}$.

A Constituição Federal de 1988 prevê, no artigo 5º os corolários do processo justo, quais sejam, a inafastabilidade do controle jurisdicional, o juiz natural, o devido processo legal, o contraditório e a ampla defesa, a publicidade, a vedação às provas obtidas por meios ilícitos, a assistência jurídica gratuita aos hipossuficientes e a duração razoável do processo.

O novo Código de Processo Civil Brasileiro, de igual modo, garante a inafastabilidade do controle jurisdicional (artigo $3^{\circ}$ ), a duração razoável do processo (artigo $4^{\circ}$ ), a isonomia (artigo $7^{\circ}$ ), o contraditório (artigos $7^{\circ}$, parte final, e artigo $9^{\circ}$ ), publicidade e eficiência $\left(\operatorname{artigo} 8^{\circ}\right)$.

Com efeito, tribunais de diferentes partes do mundo, especialmente à luz da jurisprudência da Corte Europeia de Direitos do Homem, passaram a examinar a observância, em concreto, das garantias fundamentais processuais a partir da delimitação dos contornos de um processo justo.

Fala-se na formação de uma jurisprudência transnacional, a partir de citações recíprocas entre tribunais constitucionais de diferentes países acerca da aplicação dos direitos fundamentais ${ }^{62}$.

Verifica-se que, ao perquirir que os processos judiciais apliquem concretamente o conceito de processo justo, juristas, legisladores e julgadores de diferentes nacionalidades passaram a tratar do tema relativo à garantias fundamentais do processo segundo parâmetros cada vez mais semelhantes.

Serge Guinchard, ao estudar o tema, considera estar em formação um "modelo universal de processo justo" e conclui pela existência de um direito substancial ao processo justo (procès équitable), em resposta às exigências de um Estado Democrático. Para o autor francês, isso comprova que, em nossos dias, o humanismo processual prevalece sobre o legalismo procedimental.

61 REPÚBLICA FEDERATIVA DO BRASIL. Convenção Interamericana de Direitos do Homem. Disponível, em português, no endereço elênico: https://www.cidh.oas.org/basicos/portugues/c.convencao_americana.htm Consulta realizada em 01/04/2016. ${ }_{62}$ TIBÚRCIO, Carmen. BARROSO, Luis Roberto. Direito Constitucional Internacional. Rio de Janeiro: Renovar, 2013. p. 69. 
Revista Eletrônica de Direito Processual - REDP.

Rio de Janeiro. Ano 11. Volume 18. Número 2. Maio a Agosto de 2017

Periódico Quadrimestral da Pós-Graduação Stricto Sensu em Direito Processual da UERJ

Patrono: José Carlos Barbosa Moreira. ISSN 1982-7636. pp. 261-296

www.redp.uerj.br

O autor sustenta que, nos dias atuais, para que o processo se desenvolva conforme às exigências de uma sociedade democrática e de um Estado de Direito, mostra-se necessário observar determinados princípios estruturais, notadamente contraditório, lealdade, celeridade (em conformidade com o contraditório), além de confiança e proximidade entre as sociedades democráticas modernas. Para ele, tais princípios estruturais, que marcam o conceito de processo justo, são comuns a todos os ordenamentos jurídico-processuais internos que estejam comprometidos com a democracia e devem sobrepairar aos princípios peculiares a cada sistema processual nacional.

Constata-se que os sistemas processuais nacionais são cada vez mais atraídos pelas garantias fundamentais processuais, mais especificamente pela busca de um processo justo. Esse fenômeno se opera em diferentes partes do mundo e acaba por aproximar os sistemas processuais nacionais, contribuindo para que se fale em um Direito Processual Transnacional, regido pelos mesmos princípios e valores fundamentais pelo mundo afora, conforme esclarecemos em momento anterior.

\section{A Cooperação Jurídica Internacional e o papel dos Tribunais nacionais}

O conceito de jurisdição tradicionalmente guarda estreita relação com a noção de soberania estatal. Como consequência, os provimentos jurisdicionais somente seriam passíveis de efetivação nos estritos limites territoriais e políticos do Estado a que pertence o tribunal prolator.

Essa premissa, como regra geral, era válida tempos atrás, em que o processo apresentava elementos estritamente internos, ou seja, nacionais.

No entanto, conforme destacamos anteriormente, a sociedade modificou-se substancialmente nas últimas décadas, verificando-se o aumento exponencial da circulação de pessoas, produtos, ideias e negócios entre diferentes partes do globo. Com isso, verificou-se o proporcional incremento do volume de controvérsias que oferecem elementos de estraneidade.

Desse modo, o que outrora seria meramente acidental ou ocasional ampliou-se significativamente. Passou-se a falar em sociedade globalizada e, como resposta aos anseios pela justa solução de seus conflitos, em Direito Processual Transnacional.

Assim, foi colocado em xeque o tradicional conceito de soberania. 
Revista Eletrônica de Direito Processual - REDP.

Rio de Janeiro. Ano 11. Volume 18. Número 2. Maio a Agosto de 2017

Periódico Quadrimestral da Pós-Graduação Stricto Sensu em Direito Processual da UERJ

Patrono: José Carlos Barbosa Moreira. ISSN 1982-7636. pp. 261-296

www.redp.uerj.br

Para que se possa garantir um processo justo aos jurisdicionados pertencentes a essa nova sociedade globalizada, vem-se tomando a consciência de que se afigura imperioso rever o conceito de soberania talhado sob um viés puramente doméstico. É preciso ampliar os horizontes e reconhecer que os cidadãos se relacionam, hoje, para muito além dos limites territoriais dos Estados nacionais e que, para se solucionar adequadamente os seus litígios, o problema deve ser enxergado em todo o seu espectro.

Atualmente, para que um processo seja efetivamente justo, resguardando todos os corolários que vimos de elencar, especialmente duração razoável, contraditório, ampla defesa e isonomia, é fundamental que os Poderes Judiciários dos diferentes países que são chamados a participar do processo atuem conjunta e coordenadamente, ordenando os seus esforços no sentido de solucionar a lide segundo os princípios fundamentais processuais vigentes.

O reconhecimento de outros Estados igualmente soberanos, a manutenção de uma convivência sadia na sociedade internacional e a formação de blocos de integração regional são apontados como alguns dos fatores determinantes para a releitura do conceito de soberania ${ }^{63}$.

Não obstante, o foco da cooperação jurídica internacional não se volta diretamente às relações entre os Estados, mas prioritariamente ao indivíduo, ao jurisdicionado, que é o destinatário da prestação jurisdicional e sujeito das garantias fundamentais do processo.

Os destinatários da cooperação jurídica internacional não são, portanto, os Estados, mas o indivíduo, enquanto sujeito de direito universal, a quem deve ser conferido pleno acesso à justiça, em escala global.

Sendo assim, o compromisso com a cooperação jurídica internacional deve ser promovido pelos Estados não por conveniências geopolíticas, mas em decorrência de seu compromisso com as garantias fundamentais, especialmente o acesso à justiça, enquanto corolário da dignidade da pessoa humana.

Nesse sentido, Remo Caponi assevera, com propriedade, que os ideais de justiça perquiridos pelo Direito Processual Transnacional não podem se submeter a políticas públicas circunstanciais de dado governo estatal, devendo ser perseguidos de forma perene, em favor dos jurisdicionados. As regras relativas à jurisdição não devem ser vistas

\footnotetext{
${ }^{63}$ PEREIRA, Marcus Vinícius Torres. Da admissão da litispendência internacional no conflito de jurisdições. Volume II. Rio de Janeiro: 2008. p. 511. Tese apresentada para a obtenção de grau de Doutor em Direito Internacional pela Universidade do Estado do Rio de Janeiro.
} 
Revista Eletrônica de Direito Processual - REDP.

Rio de Janeiro. Ano 11. Volume 18. Número 2. Maio a Agosto de 2017

Periódico Quadrimestral da Pós-Graduação Stricto Sensu em Direito Processual da UERJ

Patrono: José Carlos Barbosa Moreira. ISSN 1982-7636. pp. 261-296

www.redp.uerj.br

prioritariamente como um exercício da soberania, mas como uma forma de equilibrar, com razoabilidade, os interesses das partes.

Caponi pondera, ainda, que os juízes de diferentes países precisam se conscientizar de que pertencem a uma "comunidade global", no seio da qual surge uma "comunidade de tribunais". Cabe aos magistrados fomentar a mútua influência entre as diversas culturas jurídicas e a convergência de esforços para o deslinde de problemas jurídicos e a solução dos litígios transnacionais. ${ }^{64}$.

Aferrar-se ao conceito tradicional de soberania, negando ou dificultando a prática, internamente, de atos processuais que contribuem ativamente com a solução de um processo que tramita alhures consiste em conduta profundamente divorciada dos reclamos da sociedade moderna e fadada a, invariavelmente, condenar o processo ao fracasso, a um desfecho intempestivo, tardio e inefetivo.

Mauro Cappelletti destaca que a visão positivista acerca da soberania do Estado não pode prevalecer em nossos dias, cabendo aos Estados flexibilizar o seu tradicional conceito, com o escopo de instituir uma ordem internacional voltada a garantir paz e justiça em um mundo inegavelmente globalizado ${ }^{65}$.

Michele Taruffo referenda a releitura do conceito de soberania à luz do que chamou de "teoria do mundo", baseada na realidade atual de pulverização das relações jurídicas e sociais em diferentes partes do mundo, ultrapassando a tradicional noção de Estadosnações.

Acrescente-se que, dada a sua relevância para a ordem jurídica contemporânea, a cooperação jurídica internacional encontra-se prevista em diversas normas internas e internacionais.

O Tratado da União Europeia prevê a cooperação jurídica entre os Estadosmembros em matéria civil e penal nos artigos 81 e 82, respectivamente. Na esfera cível, os países signatários comprometem-se a envidar esforços no sentido de promover as seguintes providências: a) O reconhecimento mútuo entre os Estados-Membros das decisões judiciais e extrajudiciais e a respectiva execução; b) A citação e notificação transfronteiriça dos atos judiciais e extrajudiciais; c) A compatibilidade das normas aplicáveis nos Estados-

\footnotetext{
${ }^{64}$ CAPONI, Remo. "Transnational litigations and elements of fair trial". In Revista Eletrônica de Direito Processual. Ano 9. Volume 16. Jul-Dez 2016. pp 508, 510 e 517. Disponível no endereço eletrônico: http://www.e-publicacoes.uerj.br/index.php/redp/issue/view/1138

${ }^{65}$ CAPPELLETTI, Mauro. "Dimensioni della giutizia nelle società contemporanee". Op. Cit. pp. 145-146.
} 
Revista Eletrônica de Direito Processual - REDP.

Rio de Janeiro. Ano 11. Volume 18. Número 2. Maio a Agosto de 2017

Periódico Quadrimestral da Pós-Graduação Stricto Sensu em Direito Processual da UERJ

Patrono: José Carlos Barbosa Moreira. ISSN 1982-7636. pp. 261-296

www.redp.uerj.br

Membros em matéria de conflitos de leis e de jurisdição; d) A cooperação em matéria de obtenção de meios de prova; e) $\mathrm{O}$ acesso efetivo à justiça; f) A eliminação dos obstáculos à boa tramitação das ações cíveis, promovendo, se necessário, a compatibilidade das normas de processo civil aplicáveis nos Estados-Membros; g) O desenvolvimento de métodos alternativos de resolução dos litígios; h) $\mathrm{O}$ apoio à formação dos magistrados e dos funcionários e agentes de justiça ${ }^{66}$.

Os Princípios de Direito Processual Transnacional elaborados por ALI/Unidroit preveem a cooperação jurídica internacional no artigo 31, dispondo que os tribunais de qualquer Estado devem prestar assistência aos demais, com vistas a propiciar um procedimento consentâneo com os princípios enunciados, inclusive mediante a garantia de medidas urgentes e o auxílio na identificação, preservação e produção de provas ${ }^{67}$.

O artigo $1^{\circ}, \S 3^{\circ}$, da Carta das Nações Unidas de 1945 (Carta de São Francisco), de que o Brasil é signatário ${ }^{68}$, coloca a cooperação internacional entre os propósitos da Organização das Nações Unidas, com vistas a resolver os problemas internacionais de caráter econômico, social, cultural ou humanitário, e para promover e estimular o respeito aos direitos humanos e às liberdades fundamentais para todos, sem distinção de raça, sexo, língua ou religião.

Dada a importância da ONU, doutrina especializada considera que a Carta de São Francisco é aplicável não apenas aos Estados signatários, mas a toda a sociedade internacional, inclusive organizações internacionais e outros sujeitos ${ }^{69}$.

O artigo 26 da Convenção Interamericana de Direitos do Homem (Pacto de São José da Costa Rica), da qual o Brasil também é signatário, prevê a cooperação internacional voltada à plena efetividade dos direitos que decorrem das normas

${ }^{66}$ UNIÃO EUROPEIA. Versão Consolidada do Tratado sobre o Funcionamento da União Europeia. Disponível no endereço eletrônico: http://europa.eu/pol/pdf/consolidated-treaties_pt.pdf. Consulta realizada em 08/06/2016.

${ }^{67}$ AMERICAN LAW INSTITUTE. UNIDROIT. Principles of Transnational Civil Procedure. Op. Cit.

${ }^{68}$ REPÚBLICA FEDERATIVA DO BRASIL. Decreto ${ }^{\circ} 19.841$ de 22 de outubro de 1945 , que promulga a Carta das Nações Unidas. Disponível no endereço eletrônico: http://www.planalto.gov.br/ccivil_03/decreto/1930-1949/d19841.htm Consulta realizada em 08/06/2016.

${ }^{69}$ Marcus Vinícius Torres Pereira esclarece a importância da previsão contida na Carta de São Francisco: "Como a ONU congrega a quase totalidade dos Estados hoje reconhecidos como tais, a maioria da doutrina internacionalista entende que suas normas têm aplicação a toda sociedade internacional - mais ampla que o espectro de 190 Estados-membros da organização - que inclui, obviamente, os Estados, e também outros sujeitos a quem são reconhecidos direitos e/ou deveres no Direito Internacional Público, como as organizações intergovernamentais, os beligerantes, os insurgentes, o indivíduo e entes sui generis, por circunstâncias históricas e peculiares, como o Comitê Internacional da Cruz Vermelha, a Soberana Ordem de Malta e a Santa Sé. Assim, percebemos que a cooperação internacional pauta a conduta e convivência na sociedade internacional”. PEREIRA, Marcus Vinícius Torres. Op. cit. p. 513. 
Revista Eletrônica de Direito Processual - REDP.

Rio de Janeiro. Ano 11. Volume 18. Número 2. Maio a Agosto de 2017

Periódico Quadrimestral da Pós-Graduação Stricto Sensu em Direito Processual da UERJ

Patrono: José Carlos Barbosa Moreira. ISSN 1982-7636. pp. 261-296

www.redp.uerj.br

econômicas, sociais e sobre educação, ciência e cultura, constantes da Carta da Organização dos Estados Americanos ${ }^{70}$.

$\mathrm{O}$ artigo $1^{\circ}$ do Protocolo de cooperação e assistência jurisdicional em matéria civil, comercial, trabalhista e administrativa (Protocolo de Las Leñas) ${ }^{71}$, do Mercosul, de que nosso país é igualmente signatário, dispõe que os Estados Partes se comprometem a prestar assistência mútua e ampla cooperação jurisdicional em matéria civil, comercial, trabalhista e administrativa.

Nosso país é signatário, ainda, da Convenção de Nova York, voltada à cooperação jurídica internacional sobre prestação de alimentos no exterior ${ }^{72}{ }_{-}^{73}$.

Em 27 de abril de 2017 foi editado o Decreto n 9.039, que Promulga a Convenção sobre a Obtenção de Provas no Estrangeiro em Matéria Civil ou Comercial, firmada em Haia, em 18 de março de 1970. Este ato normativo trata especificamente da Carta Rogatória no capítulo primeiro.

O Código de Processo Civil Brasileiro de 2015 dedica os artigos 26 a 41 ao tema, a demonstrar a importância por ele adquirida no Direito Processual pátrio na atualidade.

No entanto, não basta que a cooperação jurídica internacional esteja encartada nos principais textos normativos. Para que represente uma efetiva conquista do jurisdicionado de nossos dias, faz-se necessário que os Estados disponibilizem instrumentos processuais aptos a facilitar o acesso à justiça no âmbito transnacional e que os tribunais nacionais estejam imbuídos do firme propósito de aplicá-los adequada e fielmente, com presteza e efetividade.

\footnotetext{
70 ORGANIZAÇÃO DOS ESTADOS AMERICANOS. Convenção Interamericana de Direitos do Homem. Disponível no $\quad$ endereço eletônico: http://www.pge.sp.gov.br/centrodeestudos/bibliotecavirtual/instrumentos/sanjose.htm Consulta realizada em 08/06/2016.

${ }^{71}$ MERCOSUL. Protocolo de cooperação e assistência jurisdicional em matéria civil, comercial, trabalhista e administrativa (Protocolo de Las Leñas). Disponível no endereço eletrônico: https://www.oas.org/dil/esp/Protocolo\%20de\%20Coopera\%C3\%A7\%C3\%A3o\%20e\%20Assist\%C3\%AAnci a\%20Jurisdicional\%20em\%20Mat\%C3\%A9ria\%20Civil,\%20Comercial,\%20Trabalhista\%20e\%20Administr ativa\%20\%E2\%80\%93\%20MERCOSUL\%20Brasil.pdf Consulta realizada em 08/06/2016.

${ }_{72}$ REPÚBLICA FEDERATIVA DO BRASIL. Decreto Legislativo $\mathrm{n}^{\circ}$ 10, de 1958, que aprova a Convenção de Nova York. Disponíveis o Decreto Legislativo e a íntegra da Convenção de Nova York, no endereço eletrônico: http://www.planalto.gov.br/ccivil_03/Constituicao/Congresso/DLG/DLG-10-1958.htm Consulta realizada em 08/06/2016.

73 MINISTÉRIO PÚBLICO FEDERAL. SECRETARIA DE COOPERAÇÃO JURÍDICA INTERNACIONAL Cartilha sobre a Convenção de Nova York. Disponível no endereço eletrônico: http://www.mpf.mp.br/atuacao-tematica/sci/pedido-de-cooperacao-1/manuais-de-atuacao-1/cartilhacny/cartilha-convencao-de-nova-iorque-cny Consulta realizada em 08/06/2016.
} 
Revista Eletrônica de Direito Processual - REDP.

Rio de Janeiro. Ano 11. Volume 18. Número 2. Maio a Agosto de 2017

Periódico Quadrimestral da Pós-Graduação Stricto Sensu em Direito Processual da UERJ

Patrono: José Carlos Barbosa Moreira. ISSN 1982-7636. pp. 261-296

www.redp.uerj.br

Sendo assim, passaremos a analisar os principais instrumentos de cooperação jurídica internacional previstos no Código de Processo Civil Brasileiro de 2015.

\section{Mecanismos de cooperação jurídica internacional no Código de Processo} Civil de 2015: um sistema preparatório para a consolidação da jurisdição transnacional

Em um mundo cada vez mais globalizado, no qual as relações interpessoais ultrapassam os limites das fronteiras, e os fatos juridicamente relevantes têm desdobramentos em diversos países, a cooperação jurídica internacional assume um papel de extrema importância tanto no Direito Processual Civil como no Direito Internacional Privado.

Conjugando esses dois tradicionais ramos do Direito, podemos falar ainda em um Direito Processual Internacional, preocupado justamente com o intercâmbio entre as diferentes jurisdições.

A latere, no plano da jurisdição nacional, diante da evolução dos meios de comunicação, a comunidade jurídica clama por uma maior eficiência no diálogo entre os juízos para que a realização dos atos processuais ocorra de forma mais célere e, consequentemente, mais efetiva ${ }^{74}$.

Além disso, em um ambiente de valorização dos meios adequados de solução de conflitos, especialmente da arbitragem, que é realizada fora do âmbito do Poder Judiciário, a relação entre estes meios e a jurisdição contenciosa fica cada vez mais complexa.

Subjacente a essas questões está a ideia, cada vez mais presente no Direito brasileiro, de cooperação. Prevista no novo Código de Processo Civil brasileiro (CPC/2015) de forma expressa como um princípio aplicável a todos os sujeitos do processo $^{75}$, não há dúvidas de que a cooperação também inspira a relação entre a jurisdição nacional e as estrangeiras; entre os diversos ramos e órgãos do Poder Judiciário, e entre o Poder Judiciário como um todo e os árbitros.

\footnotetext{
${ }^{74}$ PINHO, Humberto Dalla Bernardina de. ALVES, Tatiana Machado. A sistematização da cooperação entre os juízos no novo Código de Processo Civil, in CARNEIRO, Paulo Cezar Pinheiro; GRECO, Leonardo; PINHO, Humberto Dalla Bernardina de. Inovações do Código de Processo Civil de 2015, Rio de Janeiro: GZ, 2016, pp. 39/64.

${ }^{75}$ PINHO, Humberto Dalla Bernardina de; ALVES, Tatiana Machado. A cooperação no novo código de processo civil: desafios concretos para sua implementação. Revista Eletrônica de Direito Processual, Rio de Janeiro, v. 15, pp. 240-267, jan./jun. 2015.
} 
Revista Eletrônica de Direito Processual - REDP.

Rio de Janeiro. Ano 11. Volume 18. Número 2. Maio a Agosto de 2017

Periódico Quadrimestral da Pós-Graduação Stricto Sensu em Direito Processual da UERJ

Patrono: José Carlos Barbosa Moreira. ISSN 1982-7636. pp. 261-296

www.redp.uerj.br

Mais do que um princípio (ou cláusula geral, dependendo do entendimento) aplicável a processos específicos, a cooperação assume ares de valor basilar de todo o ordenamento jurídico ${ }^{76}$.

Isso porque, muitas vezes, no curso do processo, é necessário que um determinado ato seja praticado em outro juízo ou país. Essa situação se torna mais comum à medida que, conforme dito, se intensificam os conflitos de interesses transnacionais ${ }^{77}$.

Não é de hoje, portanto, que a questão da cooperação internacional vem sendo intensamente discutida no Brasil.

A cooperação internacional pode se realizar tanto entre autoridades judiciais, como entre autoridades administrativas, de diferentes países.

De modo geral, pode-se afirmar que a cooperação internacional visa à realização em uma jurisdição de providências de natureza jurídica que são necessárias para a efetividade de um processo que tramita (ou tramitou) em uma jurisdição diferente dessa na qual a providência será implementada.

Com relação a essas modalidades de cooperação, o autor explica que os atos não jurisdicionais, ou administrativos, não dependem do juízo de delibação para que possam ser aqui praticados, mas devem ser realizados em conjunto com autoridades judiciais ou administrativas nacionais.

Assim, a cooperação que envolve apenas a autoridade administrativa pode ser realizada na forma do auxílio direto, dispensando a atuação do Superior Tribunal de Justiça. Iremos voltar a esse ponto quando estivermos tratando do novo Código de Processo Civil brasileiro.

No Brasil, a cooperação internacional tem previsão na própria Constituição Federal de 1988, que estabelece a competência do Superior Tribunal de Justiça para processar e julgar a homologação de sentença estrangeira, e para a concessão de exequatur às cartas rogatórias (art. 105, I, alínea “i”, da Constituição Federal de 1988). ${ }^{78}$

Antes do advento do Código de Processo Civil de 2015, algumas tentativas de sistematização da cooperação jurídica internacional foram promovidas. Em 2003, a

\footnotetext{
${ }^{76}$ PINHO, Humberto Dalla Bernardina de; ALVES, Tatiana Machado. A cooperação e a principiologia no processo civil brasileiro. Uma proposta de sistematização. Revista Eletrônica de Direito Processual, Rio de Janeiro, v. 12, pp. 289-315, jul./dez. 2013.

${ }^{77}$ ARAUJO, Nadia de. Medidas de cooperação interjurisdicional no Mercosul. Revista de Processo, v. 123, p. 77, mai. 2005.

${ }^{78} \mathrm{Na}$ redação original, a Constituição Federal de 1988 atribuía essa competência ao Supremo Tribunal Federal, mas foi alterada pela Emenda Constitucional no 45, de 2004.
} 
Revista Eletrônica de Direito Processual - REDP.

Rio de Janeiro. Ano 11. Volume 18. Número 2. Maio a Agosto de 2017

Periódico Quadrimestral da Pós-Graduação Stricto Sensu em Direito Processual da UERJ

Patrono: José Carlos Barbosa Moreira. ISSN 1982-7636. pp. 261-296

www.redp.uerj.br

Associação dos Juízes Federais brasileiros elaborou o Anteprojeto de Cooperação Judiciária Internacional, voltado para a matéria penal.

Por sua vez, em 2004, o Ministério da Justiça formou uma comissão de especialistas que tinha como objetivo elaborar um anteprojeto de lei de cooperação jurídica internacional, em matéria cível e criminal. ${ }^{79}$

O novo Código de Processo Civil parece ter trazido a solução que se buscava para a questão, incorporando na legislação infraconstitucional a regulamentação que já era prevista no regimento interno do Superior Tribunal de Justiça para a homologação de sentença estrangeira e para as cartas rogatórias, e trazendo de forma expressa a previsão do auxílio direto em matéria jurisdicional.

Nesse sentido, podemos dizer que a primeira novidade do novo Código está na disposição topográfica da regulamentação da cooperação jurídica internacional, que forma o Capítulo II do Título II ("Dos limites da jurisdição nacional e da cooperação internacional”) do Livro II (“Da função jurisdicional”).

O tratamento da matéria começa com as disposições gerais (Seção I), aplicáveis a todas as modalidades de cooperação internacional. Assim, o artigo 26, caput, estabelece os princípios (devido processo legal, igualdade, acesso à Justiça, publicidade processual) e as regras estruturais (existência de uma autoridade central ${ }^{80}$ e espontaneidade na transmissão de informações a autoridades estrangeiras ${ }^{81}$ ) que regem a cooperação jurídica internacional.

Interessante observar que as normas fundamentais do ordenamento jurídico brasileiro não só determinam como o procedimento deve se desenvolver, mas também estabelecem limites para a realização da cooperação internacional, na medida em que fica vedada a prática de atos que contrariem ou que produzam resultados incompatíveis com tais normas (art. 26, § $3^{\circ}$ ).

\footnotetext{
${ }^{79}$ Para mais informações sobre o Anteprojeto de Lei de Cooperação Jurídica Internacional, v. SILVA, Ricardo Perlingeiro. Anotações sobre o anteprojeto de lei de cooperação jurídica internacional. Revista de Processo, v. 129, p. 133.

${ }^{80}$ A figura da autoridade central é atribuída ao Ministério da Justiça, quando ausente designação específica (art. 26, § $4^{\circ}$ ).

${ }^{81}$ André Luís Monteiro e Fabiane Verçosa observam que "a espontaneidade na transmissão de informações significa o dever de o Estado brasileiro, quando figurar como Estado requerido em qualquer modalidade passiva de cooperação jurídica internacional já solicitada por Estado estrangeiro, prestar informações a respeito do desenvolvimento do pedido de ofício, informando a respeito de novos andamentos e novas providências, independentemente de sucessivas provocações do Estado requerente" WAMBIER, Teresa Arruda Alvim et alii (Coord.). Breves comentários ao novo código de processo civil. São Paulo: Revista dos Tribunais, 2015, p. 122.
} 
Revista Eletrônica de Direito Processual - REDP.

Rio de Janeiro. Ano 11. Volume 18. Número 2. Maio a Agosto de 2017

Periódico Quadrimestral da Pós-Graduação Stricto Sensu em Direito Processual da UERJ

Patrono: José Carlos Barbosa Moreira. ISSN 1982-7636. pp. 261-296

www.redp.uerj.br

O CPC/2015 prevê ainda que, na ausência de tratado regulando a comunicação entre os dois países, será aplicado o princípio da reciprocidade, com exceção da homologação de sentença estrangeira, que dispensa essa exigência ( $\operatorname{art.} 26, \S \S 1^{\circ}$ e $2^{\circ}$ ).

Com relação às medidas que podem ser objeto de cooperação internacional, o artigo 27 do CPC/2015 prevê um rol não exaustivo, admitindo no inciso VI a realização de qualquer outra medida judicial ou extrajudicial que, não tendo sido citada nesse dispositivo, não seja proibida pela Lei brasileira - em outras palavras, que não ofenda as normas fundamentais do ordenamento jurídico nacional, conforme o artigo $26, \S 3^{\circ}$.

A implementação de tais avanços pelo novo Código de Processo Civil Brasileiro exerce o relevante (e histórico) papel de promover o necessário alinhamento do Brasil à moderna tendência verificada em diversos países do mundo, em prestígio à desburocratização da circulação de decisões judiciais entre países, sem, com isso, se descurar das garantias processuais.

$\mathrm{Na}$ atualidade, em que a circulação de pessoas e bens transcende, em volume crescente, as fronteiras políticas dos países, a ciência processual deve perceber e acompanhar tal evolução, sob pena de ver vulnerada a sua legitimidade. O progresso de um país e de sua população perpassa, em nossos dias, necessariamente pela forma com que o seu regramento processual e as suas instituições se posicionam em relação à circulação das decisões judiciais estrangeiras.

Garantir efetivamente o amplo acesso à justiça aos jurisdicionados já há algum tempo não pode se encerrar nos estreitos limites políticos dos países, devendo, ao revés, adquirir contornos transnacionais. E o novo CPC, sensível a isso, avança no firme propósito de trazer respostas aos novos anseios da sociedade contemporânea.

\section{REFERÊNCIAS BIBLIOGRÁFICAS}

ANDENAS, Mads. NAZZINI, Renato. ANDREWS, Neil. (Orgs.) The Future of Transnational Civil Litigation. English Responses to que ALI/UNIDROIT. Draft Principles and Rules of Transnational Civil Procedure. Londres: The British Institute of International and Comparative Law. 2006. pp. 21-40. 
Revista Eletrônica de Direito Processual - REDP.

Rio de Janeiro. Ano 11. Volume 18. Número 2. Maio a Agosto de 2017

Periódico Quadrimestral da Pós-Graduação Stricto Sensu em Direito Processual da UERJ

Patrono: José Carlos Barbosa Moreira. ISSN 1982-7636. pp. 261-296

www.redp.uerj.br

ANDREWS, Neil. The modern procedural synthesis: the American Law Institute and

Unidroit's Principles and Rules of Transnational Civil Procedure. Revista de Processo.

Vol. 164. Ano 2008. pp. 109-120.

BARROSO, Luis Roberto. 'Here, there and everywhere': human dignity in contemporary law and in the transnational discourse, Boston College International and Comparative Law Review, Vol. 35, No. 2, 2012, disponível em http://papers.ssrn.com/sol3/papers.cfm?abstract_id=1945741, acesso em 30 de janeiro de 2016.

BIAVATI, Paolo. Diritto Processuale dell'Unione Europea. 4. Ed. Milão: Giuffrè Editore. 2009.

CADIET, Loïc. JEULAND, Emmanuel. AMRANI-MEKKI, Soraya. Droit Processuel Civil de l'Union Européenne. Paris: Lexis Nexis.2011.

CAPONI, Remo. "Controversie transnazionali ed elementi di giusto processo". In Relazione generale al XIV convegno mondiale dell'Associazione internazionale di diritto processuale, Heidelberg, 26-30 luglio 2011. pp. 01-130.

CAPPELLETTI, Mauro. Dimensioni della giustizia nelle società contemporanee. Studi di diritto giudiziario comparato. Bolonha: Il Mulino. 1994.

CARPI, Federico. "Dal riconoscimento delle decisioni all'esecuzione automatica". In Rivista di Diritto Processuale. Serie II. N. 60. 2005, V. II. Bolonha: CEDAM.

CHASE, Oscar. HERSHKOFF, Helen. SILBERMAN, Linda. TANIGUCHI, Yasuhei. VARANO, Vincenzo. ZUCKERMAN, Adrian. Civil Litigation in Comparative Context. Saint Paul: Thomson West. 2007.

CHIARLONI, Sergio. Giusto processo, garanzie processuali, giustizia della decisione. Rivista Trimestrale di Diritto e Procedura Civile. Ano 2008. pp. 129.

FAZZALARI, Elio. “"Mondializzazione', politica, diritto”. Rivista Trimestrale di Diritto e Procedura Civile. ano 2000. Milão: Giuffrè. pp. 681 e ss.

FERRARESE, Maria Rosaria. Il diritto al presente. Globalizzazione e tempo delle istituzioni, Il Mulino, Bologna, 2002.

FONTANA, Cristina. La circolazione delle decisioni in materia civile e comerciale: dalla convenzione di Bruxelles al regolamento comunitario. Rivista Trimestrale di Diritto e Procedura Civile. Ano 2003. pp. 263 e ss. 
Revista Eletrônica de Direito Processual - REDP.

Rio de Janeiro. Ano 11. Volume 18. Número 2. Maio a Agosto de 2017

Periódico Quadrimestral da Pós-Graduação Stricto Sensu em Direito Processual da UERJ

Patrono: José Carlos Barbosa Moreira. ISSN 1982-7636. pp. 261-296

www.redp.uerj.br

FRIEDMAN, Lawrence. "One world: notes on the emerging legal order". In Transnational Legal Processes: Globalisation and Power Disparities. (Org) LIKOSKY, Michael. Trowbridge: Butterworths Lexis Nexis. 2002.

GUINCHARD, Serge (Org.). CHAINAIS, Cécile. DELICOSTOPOULOS, Constantin S. DELICOSTOPOULOS, Ioannis S. DOUCHY-OUDOT, Mélina. FERRAND, Frédérique. LAGARDE, Xavier. MAGNIER, Véronique. FABRI, Hélène Ruiz. SINOPOLI, Laurence. SOREL, Jean-Marc. Droit Processuel. Droits fondamentaux du process. 6. ed. Paris: Dalloz. 2011.

HAZARD, Geoffrey C. TARUFFO, Michele. STURNER, Rolf. GIDI, Antônio. "Principles and rules of Transnational Civil Procedure: Introduction to the principles and rules of Transnational Civil Procedure". In New York University Journal of International Law and Politics. Nova Iorque. v. 31. 2001.

HILL, Flávia Pereira. O Direito Processual Transnacional como forma de acesso à justiça no século XXI. Rio de Janeiro: GZ Editora, 2013

LUPOI, Michele Angelo. La 'nuova' litispendenza comunitaria: aspetti procedurali. Rivista Trimestrale di Diritto e Procedura Civile. Ano 2004. pp. 1285 e ss.

PEREIRA, Marcus Vinícius Torres. Da admissão da litispendência internacional no conflito de jurisdições. Volume II. Rio de Janeiro: 2008. p. 511. Tese apresentada para a obtenção de grau de Doutor em Direito Internacional pela Universidade do Estado do Rio de Janeiro.

PICARDI, Nicola. Giurisdizione e sovranità. Alle origini della giurisdizione statuale. Rivista Trimestrale di Diritto e Procedura Civile. Ano 2007. pp. 685.

PINHO, Humberto Dalla Bernardina de; ALVES, Tatiana Machado. A cooperação no novo código de processo civil: desafios concretos para sua implementação. Revista Eletrônica de Direito Processual, Rio de Janeiro, v. 15, pp. 240-267, jan./jun. 2015.

PINHO, Humberto Dalla Bernardina de; ALVES, Tatiana Machado. A cooperação e a principiologia no processo civil brasileiro. Uma proposta de sistematização. Revista Eletrônica de Direito Processual, Rio de Janeiro, v. 12, pp. 289-315, jul./dez. 2013.

RASIA, Carlo. Il conflitto transnazionale tra giurisdizione ordinaria e arbitrato sulla medesima lite. Spunti su un principio di « lis alibi pendens » nell'arbitrato internazionale. Rivista Trimestrale di Diritto e Procedura Civile. Ano 2004. pp. 1071 e ss. 
Revista Eletrônica de Direito Processual - REDP.

Rio de Janeiro. Ano 11. Volume 18. Número 2. Maio a Agosto de 2017

Periódico Quadrimestral da Pós-Graduação Stricto Sensu em Direito Processual da UERJ

Patrono: José Carlos Barbosa Moreira. ISSN 1982-7636. pp. 261-296

www.redp.uerj.br

SANTOS, Antônio Marques dos. Estudos de Direito Internacional Privado e de Direito Processual Civil Internacional. Coimbra: Almedina. 1998.

TARUFFO, Michele. "Dimensioni transculturali della giustizia civile". Rivista Trimestrale di Diritto e Procedura Civile. Milão: Giuffrè. 2000. Versão eletrônica anual. pp. 10471084

TARUFFO, Michele. "Note sulla dimensione transnazionale delle controversie civili". In Rivista Trimestrale di Diritto e Procedura Civile. Milão: Giuffrè. 2001. Versão eletrônica anual. pp. 1055-1080.

TARZIA, Giuseppe. "Exigences et garanties de l'exécution transfrontalière en Europe". In Justice et droits fondamentaux. Études offertes à Jacques Normand. Paris: Litec. 2003. pp. 449-459.

TROCKER, Nicolò. CHIARLONI, Sergio. CONSOLO, C. COSTANTINO, G. LUISO, F.P. SASSANI, B. N. La formazione del Diritto Processuale Europeo. Turim: G. Giappichelli Editore. 2011.

TROCKER, Nicolò. Dal «giusto processo» all'effettività dei rimedi: l'«azione» nell'elaborazione della Corte europea dei diritti dell'uomo (Parte prima). Rivista Trimestrale di Diritto e Procedura Civile. Ano 2007. pp. 35.

TROCKER, Nicolò. VARANO, Vincenzo. The Reforms of Civil Procedure in Comparative Perspective. Turim: Giappichelli Editore. 2005.

WAMBIER, Teresa Arruda Alvim et alii (Coord.). Breves comentários ao novo código de processo civil. São Paulo: Revista dos Tribunais, 2015.

WEINTRAUB, Russel J. Critique of the Hazard-Taruffo Transnational Rules of Civil Procedure, inTexas International Law Journal, vol 33, Summer 1998. 